\title{
Anti-Aging Implications of Astragalus Membranaceus (Huangqi): A Well-Known Chinese Tonic
}

\author{
Ping Liu ${ }^{1}$, Haiping Zhao ${ }^{1, \#, ~ Y u m i n ~ L u o ~}{ }^{1,2,3, *}$ \\ ${ }^{1}$ Cerebrovascular Diseases Research Institute, and Department of Neurology, Xuanwu Hospital of Capital Medical \\ University, Beijing, China \\ ${ }^{2}$ Center of Stroke, Beijing Institute for Brain Disorders, Beijing, China \\ ${ }^{3}$ Beijing Key Laboratory of Translational Medicine for Cerebrovascular Diseases, Beijing, China
}

[Received July 17, 2017; Revised August 10, 2017; Accepted August 16, 2017]

\begin{abstract}
Owing to a dramatic increase in average life expectancy and the Family Planning program of the 1970s - 1990s, China is rapidly becoming an aging society. Therefore, the investigation of healthspan-extending drugs becomes more urgent. Astragalus membranaceus (Huangqi) is a major medicinal herb that has been commonly used in many herbal formulations in the practice of traditional Chinese medicine (TCM) to treat a wide variety of diseases and body disorders, or marketed as life-prolonging extracts for human use in China, for more than 2000 years. The major components of Astragalus membranaceus are polysaccharides, flavonoids, and saponins. Pharmacological research indicates that the extract component of Astragalus membranaceus can increase telomerase activity, and has antioxidant, anti-inflammatory, immunoregulatory, anticancer, hypolipidemic, antihyperglycemic, hepatoprotective, expectorant, and diuretic effects. A proprietary extract of the dried root of Astragalus membranaceus, called TA-65, was associated with a significant age-reversal effect in the immune system. Our review focuses on the function and the underlying mechanisms of Astragalus membranaceus in lifespan extension, anti-vascular aging, anti-brain aging, and anti-cancer effects, based on experimental and clinical studies.
\end{abstract}

Key words: Astragalus membranaceus, aging, neurodegenerative disease, cancer, immnoregulation

Owing to a dramatic increase in average life expectancy and the Family Planning program of the 1970s-1990s, China is rapidly becoming an aging society. Thus, aging and aging-associated diseases, such as neurodegeneration, cardiovascular disease, and cancer, are becoming some of the most important global problems. Aging is defined as a progressive decline in intrinsic physiological function, leading to an increase in age-specific mortality rate and a decrease in age-specific reproductive rate [1]. The major theories of aging include telomere shortening theory [2], epigenetic and genetic regulation theory $[3,4]$, stem cell theory [5], mitochondrial dysfunction [6], metabolic and immune deregulation [7,8], proteostasis loss [9], and gut microbiota regulating theory [10]. Hence, targeting these pathological changes could reverse aging and treat ageassociated diseases. In traditional Chinese medicine, some herbals have been used for anti-aging since ancient times. Astragalus membranaceus (Huangqi), as one of the most important Qi tonifying adaptogenic herbs in Trational Chinese Medicine, has a long history of medicinal use. Astragalus membranaceus was originally described in the Shennong's Classic of Materia Medica, the earliest

*Correspondence should be addressed to: Dr. Yumin Luo, Cerebrovascular Diseases Research Institute, Xuanwu Hospital of Capital Medical University, Beijing 100053, China. Email : yumin111@ccmu.edu.cn. \#these authors contributed equally to this work.

Copyright: @ 2017 Lin P et al. This is an open-access article distributed under the terms of the Creative Commons Attribution License, which permits unrestricted use, distribution, and reproduction in any medium, provided the original author and source are credited. 
complete Pharmacopoeia of China written from the Warring States Period to Han Dynasty [11,12]. It is valued for its ability to strengthen the primary energy of the body which we know as the immune system, as well as the metabolic, respiratory and eliminative functions. This fact is being increasingly substantiated by pharmacological studies showing that it can increase telomerase activity, and has antioxidant, anti-inflammatory, immuneregulatory, anticancer, hypolipidemic, antihyperglycemic, hepatoprotective, expectorant, and diuretic effects [13-18]. Specifically, constituents of the dried roots of Astragalus spp. Radix Astragali provide significant protection against heart, brain, kidney, intestine, liver and lung injury in various models of oxidative stress-related disease [19,20]. In order to clarify the potential application of Astragalus membranaceus in anti-aging, we summarize the effect and mechanism of its extracts and effective component monomer against aging and age-related disease. This information could help clinicians and scientists develop novel target-specific and effective therapeutic agents that are deprived of major systemic side effects, so as to establish a better treatment regimen in the battle against aging.

\section{Phytochemistry of Astragalus membranaceus}

Astragalus membranaceus includes over 2000 species, among them, Astragalus membranaceus (Fisch.) Bge. (Fam Leguminosae) and Astragalus membranaceus (Fisch.) Bge. Var. mongholicus (Bge.) Hsiao are the most commonly used. In traditional Chinese medicine, Astragali Radix, the root of Astragalus membranaceus, was used in patients with chronic diseases and healthy persons who want to improve their body vital functions. At present, more than 200 compounds have been isolated and identified from Astragalus membranaceus. Its total polysaccharides, saponins and flavonoids fractions and several isolated compounds have been the most studied, and these bear the biological activities of Astragalus membranaceus $[21,22]$.

\subsection{Triterpenoid Saponins (Astragalosides)}

There are more than 161 saponins including about 142 kinds of cycloartane-type saponins and about 19 kinds of oleanane-type saponins. Among them, 5 major saponins, including astragalosides I, II, and IV, and isoastragaloside I and II, all being cycloartanetype triterpenoids, make up more than $80 \%$ of the total saponins. And Astragaloside IV is the qualitative control biomarker [23].

\subsection{Flavonoids}

There are more than 63 flavonoids mainly including isoflavones, isoflavans, pterocarpans, flavonols, flavones, and flavonones. Among them, isoflavones are the major constituents, and calycosin-7-O- $\beta$-D-glucoside, as one of the isoflavones, is the dominant component, and used as a chemical marker in quality analyses of Astragalus membranaceus [24]. In addition, there are 3 special flavonoids including sulfuretin, isoliquiritigenin, and pendulone.

\subsection{Polysaccharides}

Knowledge about the precise chemistry of Astragalus polysaccharides is quite limited. Since polysaccharides are macromolecules with complicated chemical structures, it is relatively difficult to isolate and characterize their individual components. There are 14 polysaccharides in Astragalus membranaceus, and 13 kinds of them have $\beta$ $\mathrm{D}-(1 \rightarrow 3)$-galactan moieties branched with $\beta$-D- $(1 \rightarrow 6)$ galactooligosaccharide side-chains[25,26].

\section{Anti-aging and anti-aging-related effects of extracts of Astragalus membranaceus}

\subsection{Oxidative stress reduction by extracts of Astragalus membranaceus}

Astragalus membranaceus can inhibit the oxidant stress by up-regulating the antioxidant factors. Aqueous extract of Astragali radix decreased the myocardial infarction size and improved the cardiac function in a myocardial ischemic rat model, which is related to the antioxidant effects via maintaining the activity of superoxide dismutase (SOD), decreasing the production of malondialdehyde (MDA) and free radical levels, and reducing cell apoptosis [27]. Besides, Astragalus injection can decrease the reactive oxygen species (ROS) and MDA levels in a rat model of cerebral ischemia through upregulating the expression of nuclear factor erythroid 2related factor 2 (Nrf-2), SOD, catalase and glutathione peroxidase (GSH-Px) [28].

\subsection{Immunomodulatory effects by extracts of Astragalus membranaceus}

Astragalus membranaceus was used to promote immune function and as a tonic to build the stamina [29]. The aqueous extract of Astragali radix also has significant immunological adjuvant activity when compounded with human vaccines [30].

Astragalus membranaceus could affect the innate immune response. The aqueous extract of Astragali radix induced the activation and migration, and monocyte 
maturation of peripheral blood mononuclear cells [31]. In the macrophage cell line RAW 264.7, aqueous extract of Astragali radix reversed the increasing iNOS expression and NO production by lipopolysaccharide (LPS), and reduced the suppression of macrophage cell proliferation by methotrexate [32]. Another research found that in the macrophage cell line ANA-1, aqueous extract of Astragali radix inhibited cytokine production via depressing p38 MAPK and NF- $\mathrm{kB}$ signaling pathways induced by advanced glycation endproduct [33].

Astragalus membranaceus could also affect the acquired immune response. The aqueous extract of Astragali radix exhibits mitogenic activities on T-cell depleted populations, augments the antibody response, and restores the lymphocyte blastogenic response in aging mice [34]. And aqueous extract of Astragali radix activated $\mathrm{CD}^{+}$and $\mathrm{CD}^{+} \mathrm{T}$ cells of humans without influencing proliferation $[35,36]$. In addition, the ethanol extracts of Astragali Radix selectively alter Th1/Th2 cytokine secretion patterns of $\mathrm{CD}^{+} \mathrm{T}$ cells through enhancing the IL-4 and IL-10 levels in Th2 cells and reducing the levels of IL-2 and IFN- $\gamma$ in Th1 cells $[37,38]$. Similarly, hydroalcoholic extract of Astragalus gypsicolus also modulated the balance of Th1/Th2 cytokines in allergic mice model [39].

Beyond that, aqueous extracts of Astragali radix promote myelopoiesis in myelosuppressed mice by improving the hematopoietic microenviroment, including enhancing the survival of bone-marrow-derived mesenchymal stem cells (BMSCs), proliferation of colony-forming unit-fibroblast through upregulation of granulocyte-macrophage colony stimulating factor and of bcl-2 expression in BMSCs [40].

\subsection{Anti-neurodegeneration by extracts of Astragalus membranaceus}

The aqueous extract of Astragali radix can reverse the memory impairment and neurodegeneration. It can increase the number of M-cholinergic receptors in the cortex, hippocampus and striate body of a senile rat model [41]. Moreover, it can prevent the loss of axons and synapses in the cortex and hippocampus, and reverse the memory loss of amyloid $\beta$-peptide $(\mathrm{A} \beta)$-induced cognitive deficits mice [42].

\subsection{Anti-tumor effect by extracts of Astragalus membranaceus}

The extract of Astragali radix, alone or combined with chemotherapeutic agents, has positive effects on the treatment of many tumors [43].

The aqueous extract of Astragali radix could inhibit the proliferation and invasion of digestive tumor cells in a dose-dependent manner. In hepatocellular carcinoma cell (HCC) line HepG2, the aqueous extract of Astragali radix combined with Salvia miltiorrhiza inhibited the invasion of tumor cells by modulating TGF-beta/Smad signaling [44]. Further research found that in the HCC rat model induced by diethylinitrosamine (DEN), the aqueous extract of Astragali radix combined with Salvia miltiorrhiza reduced the incidence and multiplicity of HCC development in a dose-dependent manner by inhibiting fibrosis and the transcription of plasminogen activator inhibitor-1 [45,46]. In addition, the aqueous extract of Astragali radix can inhibit the growth of human gastric cancer cell lines AGS and KATO-III in a time-and dose-dependent manner [47]. It was further found that Astragalus injection can reduce the apoptosis by increasing the $\mathrm{Bcl}-2$ expression and reducing the Bax expression in gastric cancer cell supernatant-induced peritoneal mesothelial cells [48].

Extract of Astragali radix also has anti-tumor effects against lung cancer, renal cell carcinoma, and bladder cancer, as shown in clinical trials and animal experiments. The Astragalus-based traditional Chinese medicine formula increased the effectiveness and reduced the toxicity of standard platinum-based chemotherapy in 2,815 patients with advanced non-small-cell lung cancer [49]. In addition, aqueous extracts of Astragali radix may have exerted their antitumor effects via augmentation of phagocyte and LAK cell activities in mice bearing renal cell carcinoma [50]. Similarly, aqueous extract of Astragali radix lowered the incidence of urinary bladder carcinoma through activating the cytotoxicity of lymphocytes and increasing the production of IL-2 and IFN- $\gamma$ in mice [51]. Therefore, immune regulation is one of its main mechanisms of anticancer protection.

\section{Anti-aging and anti-aging-related effects of Astragalus membranaceus saponins (AMS)}

\subsection{Total AMS}

\subsubsection{Immunomodulatory effects of total AMS}

AMS not only regulate the activity of immune cells, but also regulate the expression of adhesion molecules on the surface of endothelial cells. AMS can suppress LPSinduced iNOS and TNF- $\alpha$ expression in the mouse macrophage RAW264.7 via suppressing p38 MAPK/NF$\kappa B$ signaling [52]. In primary mouse kidney arterial endothelial cells, total AMS attenuated TNF $\alpha$-induced upregulation of cell adhesion molecules, activation of NF$\kappa \mathrm{B}$, degradation of inhibitor of $\kappa \mathrm{B} \alpha(\mathrm{I} \kappa \mathrm{B} \alpha)$, and inhibited pro-apoptotic signaling pathway by reducing cell surface 
TNFR1 level [53].

\subsubsection{Anti-tumor by total AMS}

The anti-cancer effects of total AMS have been investigated in digestive system tumors [53-58].

AMS can inhibit the proliferation and induce apoptosis of colon cancer. AMS inhibited cell proliferation by accumulation in S phase and G2/M arrest and promoted apoptosis in human colon cancer cells HT29. It targeted NSAID-activated gene, causing overexpression of nonsteroidal anti-inflammatory drug activated gene-1 (NAG-1) and the caspase activation through modulation of an ERK independent NF- $\mathrm{KB}$ signaling pathway [56,59]. AMS also exerted anticarcinogenic activity through modulating the PI3K/Akt/mTOR and ERK signaling pathways in colon cancer cells HCT 116 and HT-29 [57,60]. Another study found AMS could induce endoplasmic reticulum (ER) stress-mediated apoptosis by elevating the level of XBP1 and CCAAT/enhancer-binding protein-homologous protein [61].

In human gastric adenocarcinoma cells, AMS arrested cell cycle at the $\mathrm{G} 2 / \mathrm{M}$ phase through regulating cyclin B1, p21 and c-myc [58]. Besides its pro-apoptotic and anti-proliferative activities, AMS can modulate the invasiveness and angiogenesis of tumor cells, by downregulating the VEGF and metastatic proteins metalloproteinase (MMP)-2 and MMP-9, which suggested that AMS may be used for the treatment of advanced and metastatic cancers [58].

\subsection{Astragalosides (AST)}

AST are cycloartane triterpenoid saponins which are characterized by 3-, 6- and/or 25-conjugated glucose moieties and whose 3 -glucose is acetylated.

\subsubsection{Anti-aging effect of AST}

AST delay the senility in the aging rat induced by hydrocortisone through the antioxidant and immunoregulatory effects [62]. Moreover, treatment with AST for 10 weeks could delay senility and ameliorate agerelated alternations in both motor response and memory in the D-galactose-induced senescent mouse and the preaged (17-month-old) mouse [63]. The anti-aging mechanism was suggested to act by restoring the activities of MnSOD and GSH/GSSG ratio, as well as enhancing the thymus index and splenocytes proliferation [63]. AST also protected human skin fibroblasts against ultraviolet A (UVA)-induced photoaging, reducing the senescenceassociated $\beta$-galactosidase positive cell rate via decreasing the level of MMP-1 and increasing the expression of tissue inhibitor of metalloproteinase- 1 and transforming growth factor- $\beta 1$ (TGF- $\beta 1)$ [64].

\subsubsection{Immunomodulatory effects of AST}

AST promote both humoral and cellular immune responses of chicken vaccinated with Newcastle disease [65]. Also, AST increased CD45 phosphatase activity in mice primary splenocytes and $\mathrm{T}$ cells [66].

\subsubsection{Anti-vascular disease by AST}

AST have positive effects on cardio-cerebrovascular diseases. AST promoted angiogenesis through increasing the expression of VEGF and bFGF in the rat myocardial infarction model [67]. AST also improved left ventricle function and cardiac structure of chronic heart failure rats through reversing the depression of sarcoplasmic reticulum $\mathrm{Ca}^{2+}$-ATPase activity, and increasing phosphorylated phospholamban, similar with the result of previous studies in cultured cardiac myocytes of neonatal rats $[68,69]$. In the rat model of focal cerebral ischemiareperfusion injury, AST protected against neurological deficit by regulating the expressions of iNOS, nerve growth factor and tropomyosin receptor kinase A [70]. Further research found that AST blocked apoptosis in the PC12 cells of OGD model by suppressing functional impairment of mitochondria and ER stress through regulating the P38 MAPK signaling pathway [71].

\subsubsection{Anti-neurodegeneration by AST}

AST improved learning and memory in the AD model of 12 month old male rats through down-regulating the expression of APP, $\beta$-secretase and $A \beta(1-40)$ in hippocampus [72]. In addition, AST attenuated A $\beta 25-35-$ induced cytotoxicity degeneration of primary rat cortical cells, inhibited apoptosis, synaptotoxicity, and mitochondrial dysfunction via modulation of both PI3K/AKT and ERK pathways [73]. In addition, AST also improved the learning and memory abilities in a cerebral ischemia rat model by attenuating neuronal cells apoptosis though increasing the expression of $\mathrm{p}$-ERK and p-Akt, decreasing the expression of p-JNK [74].

\subsubsection{Anti-tumor effects by AST}

There is little research done concerning the effects of AST on tumors. Yet, it was shown that AST pronouncedly inhibited the proliferation of human gastric cancer MKN74 cells in a dose and time-dependent manner [75]. 


\subsection{Astragaloside II (AST-II)}

AST-II is a principal component of astragalosides purified from Radix Astragali. Its chemical structure is (3b,6a, 16b,20R,24S)-3-((2-O-Acetyl-betaD-xylopyxylopyranosyl)oxy)-20,24 -epoxy-16,25-dihydroxy-9,19cyclolanostan-6-ylbeta-D-glucopyranoside), and its molecular formula is $\mathrm{C} 45 \mathrm{H} 72 \mathrm{O} 16$, which can regulate the immune response and inhibit tumor.

\subsubsection{Immunomodulatory effects of AST-II}

In both cyclophosphamide-induced immunosuppressed mice and primary splenocytes and T cells, AST-II promoted ConA- and alloantigen-induced $\mathrm{T}$ cell proliferation and activation via regulating the activity of CD45 PTPase and initiating the activation cascade via CD45-mediated dephosphorylation of the Lck tyrosine kinase [66]. But AST-II has no obvious effects on LPSinduced B cell proliferation. Although AST-II is an immunological adjuvant, it is the most toxic Astragalus component with 5-10\% weight loss in mice [76].

\subsubsection{Anti-tumor by AST-II}

AST-II is a multidrug resistance (MDR) reversal agent and a potential adjunctive agent for hepatic cancer chemotherapy. In the human hepatic cancer Bel-7402 and Bel-7402/FU cells, AST-II downregulated the expression of mdr1 gene and P-glycoprotein, suppressed autophagy by interfering with Beclin-1 and LC3 via MAPK-mTOR pathway, through which it sensitized human cancer resistant cells to 5-FU-induced cell death [77,78].

\subsection{Astragaloside IV (AST-IV)}

AST-IV is a principal component of astragalosides. Chemical structure of AS-IV is 3-O-beta-D-xylopyranosyl-6-O-beta-D-glucopyranosyl-cycloastragenol, a lanolin alcohol-shaped tetracyclic triterpenoid saponin with high polarity, and its molecular formula is C14H68O14. In beagle dogs, the absolute bioavailability of AST-IV by oral is only $7.4 \%$, and its plasma protein binding rate is about $90 \%$ [79]. And the reasons include its poor intestinal permeability, high molecular weight, low lipophilicity and its paracelluar transport [80].

\subsubsection{Anti-aging effect of AST-IV}

AST-IV is an effective agent for the prevention of photoaging. It enhances the viability of skin cells irradiated with UVA, suppresses the expression of MMP1 and prevents the degradation of type I procollagen through suppression of MAPK and NF- $\mathrm{B}$ pathway and regulating TGF- $\beta /$ Smad pathway $[81,82]$.

\subsubsection{Immunomodulatory effects of AST-IV}

AST-IV enhances immune function as an immunological adjuvant with no toxicity and has anti-inflammatory effect [76]. AST-IV increased the proliferation of $\mathrm{T}$ and $\mathrm{B}$ lymphocytes and antibody production but inhibits the production of IL-1 and TNF- $\alpha$ from peritoneal macrophages [83]. AST-IV inhibits the function of highmobility group box 1 , and shifts of Th2 to Th1 through upregulating Foxp 3 expression on $\mathrm{CD} 4{ }^{+} \mathrm{CD} 25^{+}$regulatory T cells (Tregs) [84,85]. AST-IV and cycloastragenol could upregulate telomerase activity, improve the proliferation and enhance immune function of CD8 $+\mathrm{T}$ lymphocytes from HIV-infected patients [86], through activating $\mathrm{Src} / \mathrm{MEK} / \mathrm{ERK}$ pathway in a time- and dose-dependent manner [87].

AST-IV also has anti-inflammatory activity in endothelial cells. AST-IV significantly inhibited LPSand TNF $\alpha$-induced expression of E-selectin and VCAM1 through inhibiting the NF-אB pathway [88].

\subsubsection{AST-IV effects on vascular-related diseases}

In acute myocardial infarction rat model, AST-IV preserved the cardiac function, decreased the infarcted size and inhibited the left ventricular fibrosis [89]. ASTIV decreased the ROS and MDA levels by upregulating the content and activity of GSH-Px and SOD in neonatal rat primary cardiomyocytes [90,91]. AST-IV can attenuate the inflammatory cytokines by down-regulating the TLR4/NF-кB pathway, up-regulating Sonic hedgehog pathway and the TGF- $\beta$ expression $[92,93]$.

In the murine cerebral ischemia model, AST-IV reduced infarct volume, and improved neurological outcome by decreasing the expression of peripheral benzodiazepine receptors [94]. AST-IV down-regulated the MDA content and ROS production, restores the activity of SOD and GSH-PX $[95,96]$. AST-IV alone or combined with ginsenoside Rg1, ginsenoside Rb1 and notoginsenoside R1, strengthened the antagonistic effects on oxidative stress injury through activating Nrf2/HO-1 pathway [97,98]. In addition, AST-IV prevented neutrophils accumulation in the brain parenchyma, and downregulated inflammatory reaction by inhibiting NFкB [99].

AST-IV has the angiogenic effect in pathological conditions. In human umbilical vein, endothelial cells (HUVECs) exposed to hypoxia, AST-IV promoted cell proliferation and migration, and increased tube formation [100]. It might be that AST-IV enhanced the expression 
of VEGF and kinase domain region/fetal liver kinase1/VEGF receptor 2 (KDR/Flk-1/VEGFR2) [101]. And pretreatment with AST-IV in $\mathrm{H}_{2} \mathrm{O}_{2}$-induced HUVECs showed antioxidant properties via inhibiting NADPH oxidase-ROS-NF- $\kappa B$ pathway [102]. However, some other study found that in vascular human dermal vascular smooth muscle cells induced by platelet-derived growth factor, AST-IV inhibits the proliferation and migration by down-regulating MMP2 and the p38 MAPK signaling pathway [103]. These contradictory results may be due to their use of different cells, and this issue needs further research in vitro and in vivo.

\subsubsection{AST-IV protective effects neurodegeneration and cognitive decline}

against

In the $\mathrm{AD}$ mouse model, AST-IV could improve the learning and memory deficits, inhibit $A \beta$ plaque accumulation in the brain of APP/PS1 mice [104]. ASTIV prevents $A \beta 1-42$-induced neurotoxicity and increases cell viability of SK-N-SH cells. This may be because AST-IV maintained the function of mitochondria such as increasing $\Delta \Psi \mathrm{m}$, the ATP level and the cytochrome $\mathrm{c}$ oxidase activity through inhibiting mPTP opening, inhibited the mitochondria-mediated apoptotic process [105]. Both in vivo and in vitro, AST-IV treatment inhibits the expression of $\beta$-site amyloid precursor protein cleaving enzyme 1 (BACE1) by activating peroxisome proliferator-activated receptor gamma (PPAR $\gamma$ ) [104]. AST-IV also attenuated memory impairment induced by bilateral common carotid artery occlusion in mice. It attenuated neuronal apoptosis, suppressed oxidative damage, reduced the over activation of microglia and astrocyteы in the hippocampus, down-regulated the NLRP3 inflammasome overactivation by reducing the expression of toll-like receptor-4 (TLR4) and the phosphorylation of NF-kB $[106,107]$. The neural stem cell (NSC) transplantation is a potential therapeutic approach for $\mathrm{AD}$. In an AD model transplanted with NSC into the hippocampus, AST-IV increased the proliferation of NSC and immature neurons and promoted the learning and memory by up-regulating Notch-1 and downregulating presenilin-1 (PS-1) [108].

AST-IV may reverse behavioral deficits associated with PD. In the in vitro PD model of primary nigral neuron cells induced by 6-hydroxydopamine (6-OHDA), AST-IV attenuated the loss and degeneration of dopaminergic neurons, increased the number of tyrosine hydrolase immunopositive neurons, and increased the NOS level of dopaminergic neurons [109]. In the in vitro PD model of SH-SY5Y cells induced by 1-methyl-4phenylpyridnium ion $(\mathrm{MPP}(+))$, pretreatment with ASTIV attenuated the cell death and increased the cell viability, by down-regulating the $\mathrm{Bax} / \mathrm{Bcl}-2$ ratio and the activation of cleaved caspase-3 [110].

In addition, one of the therapeutic targets for neurodegenerative diseases is inhibiting microglia activation. AST-IV can inhibit microglia activation by activating the glucocorticoid pathway, suggesting its possible therapeutic potential [111].

\subsubsection{Anti-tumor effects by AST-IV}

AST-IV reduced the proliferation, migration and invasion of several tumors.

In HCC cell lines HepG2, AST-IV inhibited the colonogenic survival and anchorage-independent growth of cancer cells, down-regulated the expression of oncogene Vav3.1 in a dose- and time-dependent manner [112]. AST-IV also attenuated the migration and invasion of Huh7 and MHCC97-H cell line through inhibiting the epithelial mesenchymal transition by targeting the Akt/GSK-3 $\beta / \beta$-catenin pathway [113]. Moreover, in orthotopic HCC mouse model, AST-IV significantly reduced the tumor weight, decreased the count of tumor microvessels and the expression of angiogenic factors including MMP2, FGF2, VEGF, and HGF, which might be due to up-regulating a tumor suppressor gene miR-122, while down-regulating an oncogene miR-221 [114].

In a lung cancer mice model induced by indoleamine 2,3-dioxygenase, AST-IV suppressed the tumor growth, interfered with T-cell immunity by decreasing Tregs and increasing cytotoxic $\mathrm{T}$ lymphocytes among the splenetic mononuclear cells [115]. In vitro, AST-IV inhibited the migration and invasion of lung cancer A549 cells, regulated the expression of MMP-2, MMP-9 and decreased the inflammation factors TNF- $\alpha$ and IL- 6 through downregulating the PKC- $\alpha$-ERK1/2-NF- $\mathrm{BB}$ pathway [116]. In breast cancer cell line MDA-MB-231, AST-IV inhibited the viability and invasion of tumor cells, downregulated the expression of Vav3, MMP-2, and MMP-9 through suppressing the activation of ERK1/2 and JNK [117].

AST-IV enhances the chemosensitivity of chemotherapeutic drugs in cancers. In colorectal cancer, AST-IV inhibits the growth of cancer cells with no cytotoxicity in normal colonic cells, and increases the chemosensitivity of cancer cells to cisplatin through inhibition of NOTCH3 [118]. In human non-small cell lung cancer cell lines, high doses of AST-IV inhibited cell growth, and increased chemosensitivity to cisplatin by down-regulating the mRNA and protein levels of B7-H3 [119].

In summary, AST-IV exerts anti-tumor effects; it may be a stand-alone alternative therapy for tumors with no side effects, or a part of combined therapy together 
with chemotherapeutic drugs.

\section{Anti-aging and anti-aging related effects of Astragalus flavonoids (AF)}

Flavonoids are the largest group of polyphenolic compounds of Astragalus membtanaceus. They include flavones, flavonols, flavanones, flavanonols, chalcones, aurones, isoflavonoids and pterocarpans. Among them, isoflavonoids are divided into two groups: isoflavones and isoflavanes.

\subsection{Immunomodulatory effects of AF}

Oral treatment with AF for 6 weeks enhances immune function through ameliorating the reduced spleen cell proliferation and balancing the abnormal cytokine levels in rats with induced chronic fatigue syndrome [120]. In addition, AF promotes the proliferation and activation of natural killer cell line NK-92, upregulates the expressions of activating receptors NKG2D, NKp44 [121]. AF also has significant anti-inflammatory effects and immunological adjuvant activity [76]. AF inhibited the production of the proinflammatory cytokines IL-6 and IL12 p40 in bone marrow-derived dendritic cells (DCs) stimulated by LPS [122]. And AF showed anti-NO activity in mouse macrophage RAW264.7 cells stimulated by LPS [123]. Further study indicated that formononetin, one of isoflavonoids, significantly inhibited the production of $\mathrm{NO}$ and the expression of iNOS and cyclooxygenase-2 (COX-2) in LPS-stimulated RAW 264.7 cells $[124,125]$.

\subsection{Oxidative stress reduction by AF}

In the atherosclerotic rabbit model induced with high cholesterol feeding, AF reduced the plasma levels of total cholesterol and LDL-cholesterol, increased the level of HDL-cholesterol, scavenged superoxide and hydroxyl radicals, and reduced the aortic fatty streak area [126]. In the hemorrhagic shock/reperfusion injury rabbit model, AF had a protective effect on ischemia/reperfusion injury by blocking the decrease of $\mathrm{NO}$ and maintaining the acidbase balance of the body [127].

Isoflavonoids, including formononetin, calycosin and calycosin 7-O-glc, have neuronal protections in a PC12 cell model by scavenging free radicals generated by DPPH in a dose-dependent manner [128]. The antioxidant activity of isoflavonoids include preventing the decrease in the activity of antioxidant enzymes, decreasing membrane fluidity to stabilize membranes, chelating iron and copper ions involved in free radical production, scavenging ROS [128-131].

\subsection{Anti-neurodegeneration and cognitive decline by AF}

In vitro, neurodegenerative disorder model is induced by $\mathrm{N}$-methyl-D-asparate (NMDA) in primary-cultured cortical neurons. As a novel herbal isoflavonoid isolated from Astragalus membranaceus, formononetin protects neurons and attenuates the apoptotic cells by increasing the levels of Bcl-2 and pro-caspase- 3 and decreasing the levels of Bax and caspase-3 [132].

\subsection{Anti-tumor effects by AF}

AF can be used to treat many tumors, due to their effects of inhibiting the proliferation and metastasis of tumor cells, and apoptosis induction.

In human hepatocarcinoma cells SMMC-7721 and HepG2, AF inhibited the growth of tumor cells by arresting cell cycle in the G0/G1 and S phases, inducing apoptosis via mitochondria-dependent and death receptordependent apoptotic pathways [133]. In the hepatic cancer rat model induced by $\mathrm{N}$-diethylnitrosamine, a flavonol glycoside rhamnocitrin $4{ }^{\prime}-\beta$-d-galactopyranoside can prevent hepatocellular carcinogenesis by increasing the activity of antioxidant enzymes, such as SOD, CAT, GPx, GST and reducing the level of lipid peroxidation [134,135].

In human colon cancer, AF has pro-apoptotic and anti-tumorigenic activities, and elicits NAG-1 overexpression, a divergent member of the TGF- $\beta$ superfamily which is correlated with growth inhibition and apoptosis induction [136,137]. Apigenin and quercetin, two flavone aglycones isolated from Astragalus verrucosus Moris have dose-dependent cytotoxic effects on human colon carcinoma cell line HCT116 [138]. Formononetin, another active compound, inhibits the cell growth and promotes apoptosis by caspase activation and downregulation of the $\mathrm{Bcl}-2$ and Bcl-xL in HCT116 cells [139].

In nude mice inoculated with breast cancer cell line, AF prolongs the survival time, and inhibits the proliferation and metastasis of tumor cells in a dosedependent manner [140]. AF and an isoflavone aglycone calycosin inhibit the proliferation through arresting cell cycle in the G0/G1 phase by decreasing cyclin D1 in human erythroleukemia cell line K562 [141]. Another flavonol glycoside, rhamnocitrin 4'-D-galactopyranoside, indicates the anti-proliferative effect in T-cell leukemia cells SKW-3 [142].

5. Anti-aging and anti-aging-related effects of Astragalus polysaccharides (APS) 


\subsection{Total APS}

\subsubsection{Anti-aging effects by APS}

APS have anti-aging activity. In Caenorhabditis elegans, APS can extend healthy lifespan by up-regulating the miR-124 which targets an endoplasmic reticulum stressregulated transmembrane transcription factor ATF-6 [143]. In male BALB/c mouse and D-galactose-induced aging mouse, APS increased the activity of SOD, GSH-Px, and CAT, decreased MDA production, and upregulated the thymus index and the spleen index $[144,145]$.

\subsubsection{Antioxidant stress by APS}

APS shows both in vitro and in vivo antioxidant activities $[146,147]$. APS increases the levels of SOD, glutathione and total antioxidant capacity and anti-hydroxyl radical activities, inhibiting the MDA formation [148]. APS inhibits the mitochondrial permeability transition, protects mitochondria from oxidative damage, and increases the activities of the antioxidases in mitochondria of mouse liver and brain [145].

\subsubsection{Immunoregulation by APS}

APS possess an excellent immunopotentiatory property in both humoral immunity and cellular immunity [149]. In the common carp, APS up-regulates the gene expressions of IL- $1 \beta$, TNF- $\alpha$ and lysozyme-C in the kidney, gill and spleen in a dose-dependent manner [150]. APS could also enhance the expression of IL-2, IL-3, IL-4, IFN- $\gamma$, IgM and $\operatorname{IgG}$ but decrease IgE [151-153].

Dendritic cells (DC) are special antigen presenting cells, and can initiate the primary immune response. APS prompts DCs maturation and their ability of antigen presentation and reduces the endocytic activity of DCs [154]. APS could also induce the differentiation of DCs and subsequently activate T cells [155]. APS can regulate the T cell immunity. APS can inhibit the activity of Tregs through binding anti-TLR4 on Tregs, and trigger a shift from Th2 to Th1 with activation of $\mathrm{CD}^{4+} \mathrm{T}$ cells $[156,157]$. Besides, APS can activate B lymphocytes via membrane Ig in a TLR4-independent manner [158].

APS can activate mouse macrophages through triggering TLR4-mediated signaling pathways which upregulate the expression of p-p38, p-ERK, p-JNK, induce I $\kappa \mathrm{B}-\alpha$ degradation and NF- $\kappa \mathrm{B}$ translocation, then finally enhance the production of TNF- $\alpha$, IL- 6 , and NO $[158,159]$. APS also increases the level of granulocytemacrophage colony-stimulating factor in mouse macrophages by activation of NF- $\mathrm{KB} / \operatorname{Rel}[160,161]$. APS can increase the number of mouse peritoneal macrophages and the deposition of the $\mathrm{C} 3$ [162]. APS also increases $\mathrm{Ca}^{2+}$-cAMP and TLR4/NF- $\mathrm{BB}$ signaling pathways in RAW 264.7 cells [163]. By contrast, APS suppress the expression of TNF- $\alpha$ and IL- $1 \beta$ by inhibiting NF- $\kappa B$ activation in the THP-1 macrophages stimulated by LPS [164]. And APS can ameliorate palmitate-induced proinflammatory responses through up-regulating the antiinflammatory genes expression and down-regulating the pro-inflammatory genes expression via the AMPK signaling pathway [165].

APS is an immune adjuvant and can help vaccine to provide a longer-term protection. APS enhances the immune responses when combined with hepatitis B virus DNA vaccine or recombinant hepatitis B surface antigen vaccine. APS could resist the immunosuppression in a chicken model induced by cyclophosphamide through promoting T-lymphocyte proliferation and raising the serum levels of antibody titers [152]. In chickens vaccinated with Newcastle disease, APS liposome promotes the lymphocyte proliferation, and enhances antibody titer [166]. In an vivo model immunized with foot-and-mouth disease virus vaccine, APS was able to upregulate both the cellular and humoral immune response via increasing the phagocytic capacity of peritoneal macrophages, DCs maturation, T-lymphocyte proliferation, expression of cytokines and antibody production, enhancing the number of $\mathrm{T}$ helper memory cells, cytotoxic $\mathrm{T}$ cells, and natural killer cells among peripheral blood lymphocytes $[167,168]$.

\subsubsection{APS protective effects against vascular diseases}

APS inhibits apoptosis, and adhesion function damage in TNF- $\alpha$-treated HUVECs through downregulating the expression of ICAM-1 and VCAM-1 via suppressing NF$\kappa \mathrm{B}$ activation [169]. APS inhibits the inflammatory response of rat bone marrow endothelial progenitor cells (EPCs) induced by thrombin, suppresses the expression of ICAM-1 by blocking NF- $\kappa$ B signaling and up-regulating expression of VEGF and its receptors Flt-1, KDR [170]. APS inhibits the cell apoptosis of human cardiac microvascular endothelial cells induced by $\mathrm{Na}_{2} \mathrm{~S}_{2} \mathrm{O}_{4}$ via enhancing the levels of SOD, Bcl-2, PI3K/AKT, reducing the levels of ROS, $\mathrm{Ca}^{2+}$, MDA and Bax, and inhibiting the activity of caspase-3 [171]. In the foam cells, APS promotes the expression of ATP-binding cassette transporter $\mathrm{A} 1$, increases cholesterol effluent rate, and attenuates NF- $\kappa B$ nuclear translocation induced by TNF$\alpha$ [172]. And in high-fat diet mouse, APS reduces plasma cholesterol by up-regulating the expression of cholesterol metabolism associated gene cholesterol- $7 \alpha$-hydroxylase and LDL-receptor, increasing fecal bile acid and neutral sterol excretion and inhibiting intestinal fractional 
cholesterol absorption [173]. All of these indicate that APS may have antiatherosclerotic activity. In addition, APS could promote angiogenesis. In hind limb ischemia rats, APS administered intramuscularly could increase the expression of VEGF, VEGFR-1, VEGFR-2, Ang-1 and Tie-2 [174].

\subsubsection{Prevention of neurodegeneration and cognitive decline by APS}

In C. elegans and cell models, APS reduces polyglutamine aggregation and alleviates the neurotoxicity through the DAF-16/FOXO transcription factor which is known to regulate the lifespan [175]. APS can reverse the memory impairment in the diabetic model, and the potential mechanisms are associated with their antioxidant properties, influence on insulin resistance and the regulation of lipid and glucose metabolism [176]. APS attenuates the inflammatory responses of BV2 induced by LPS, for example, reduces the production of IL-1b, TNF$\alpha$, and NO, inhibits COX-2 gene expression, via suppression of NF-kB signaling pathways [177].

\subsubsection{Anti-tumor effects by APS}

APS exhibit anti-tumor activities, such as inhibiting proliferation, promoting apoptosis, regulating immune response.

APS can improve the quality of life of patients with digestive system cancer. In patients with esophageal cancer, APS combined with radiotherapy can improve the quality of life and reduce the incidence of nausea and leucopenia [178]. Meta-analysis indicated that in patients with gastric cancer, APS combined with chemotherapy can strengthen the most the overall response rate, improve the quality of life, reduce the incidence of nausea, vomiting and leukopenia [179]. APS can stimulate immunity activities in rats with gastric cancer by increasing the proliferation of spleen lymphocytes, the number of $\mathrm{CD}^{4+} / \mathrm{CD}^{8+} \mathrm{T}$ cells, NK activities, and the levels of IL-2, IgA, IgG and IgM [180]. In addition, APS inhibit the proliferation of HepG2 cell line, induce apoptosis and arrest cell cycle in the G1 and sub G1/apoptotic phases [181,182]. Consistent with this, APS decrease cell viability and induce the apoptosis of $\mathrm{H} 22$ cells through regulating the expression of Bcl-2 and BAX, and of caspase by inhibiting Notch1 expression [183]. Moreover, APS enhance the chemosensitivity in $\mathrm{H} 22$ cells resistant to Adriamycin by downregulating the reversal of mdr1 expression and inhibiting the P-glycoprotein efflux pump function [184]. In H22-bearing mice, APS produce a tumor inhibition rate of $59.01 \%$, increase the spleen and thymus indexes, and promote cell apoptosis by increasing
Bax and decreasing Bcl-2 expression, improve the phagocytotic function of macrophages $[185,186]$. In the human HCC tissue, APS can restore the cytokine balance, decrease the population of $\mathrm{CD} 4{ }^{+} \mathrm{CD} 25^{\text {high }}$ Treg cells and their proliferation by downregulating FOXP3 expression, and reduce the migration by inhibiting the secretion of the chemokine SDF-1 in a dose- and time-dependent manner [187]. APS also improve proliferation and activity of intestinal intraepithelial $\gamma \delta \mathrm{T}$ cells in tumor-bearing mice by increasing the levels of IFN- $\gamma$, FasL and GrB in $\gamma \delta \mathrm{T}$ cells [188]. In addition, APS inhibit the tumor cell growth in Kunming mice with Ehrlich's ascites carcinoma, decrease Bcl-2 and CDK4 levels, increase the percentage of $\mathrm{CD}^{3+}$ and $\mathrm{CD}^{4+} \mathrm{T}$-lymphocytes, the ratio of $\mathrm{CD}^{4+} / \mathrm{CD}^{8+}$ $T$ cells and the expression of IL-2/IL-2R in spleen and Bax in tumor tissue [189].

APS can also improve the quality of life of patients with respiratory system tumor. In the nasopharyngeal carcinoma cell lines and in the xenograft model, APS promoted the anti-proliferative and apoptotic effects of cisplatin in a dose-dependent manner by upregulating the $\mathrm{Bax} / \mathrm{Bcl}-2$ ratio and increasing the expression of caspase [190]. In 136 patients with advanced NSCLC, APS injection integrated with vinorelbine and cisplatin, was able to decrease the fatigue, nausea and vomiting, pain and loss of appetite. However, there was no statistically significant change in objective response rate, median survival time and 1-year survival rate [191]. In human NSCLC cell line H460 and tumor tissue from patients with NSCLC, APS inhibited the proliferation and promoted cell apoptosis in a dose and time-dependent manner through suppressing the expression of notch1 and notch3, up-regulating the expression of p53, p21, p16, Bax and caspase-8 [192]. APS can inhibit the tumor growth of mice bearing Lewis lung carcinoma, downregulate the expression of CD44 protein, reduce collagen type IV and hyaluronic acid content, and enhance the therapeutic effect of cisplatin [193].

APS inhibit the proliferation of breast cancer cell line MDA-MB-468 through up-regulating the expressions of p53 and PTEN by regulating p53/murine double minute 2 positive and negative feedback loops [194]. In EAC breast tumor-bearing mice, APS can decrease the tumor weigh, increase immune organ indexes through activation of TLR4-mediated MyD88-dependent signaling pathway [195].

APS could prevent the side effects of chemotherapy drugs in cancer treatment, such as liver injury, cardiotoxicity and neutropenia. APS inhibit the hepatotoxicity induced by frequently-used chemical therapy agents [196]. APS could ameliorate doxorubicininduced cardiotoxicity through restoring normal autophagic flux via regulating the AMPK/mTOR pathway, 
or reduce doxorubicin-induced cell apoptosis and ROS production via regulating the $\mathrm{p} 38$ pathway and PI3k/Akt pathway [197-199]. When neutropenia appeared in chemotherapy, APS can increase the numbers of polymorphonuclear leukocytes, and promote the differentiation and chemotactic ability of bone marrow granulocytes via the L-selectin signaling pathway [200].

\subsection{Astragalan}

Astragalan is an acidic polysaccharide isolated from Astragalus membranaceus.

\subsubsection{Anti-aging effect of Astragalan}

Astragalan can offer protection against oxidative stress, by increasing antioxidant enzyme activities and decreasing peroxidative lipid levels [146,147]. In rodent models, astragalan reduces ER stress, regulates insulin/IGF-1 pathway, and thereby restores glucose homoeostasis [201,202]. Also, the regulation of insulin/IGF-1 pathway can extend lifespan [203]. In wildtype and polyglutamine (polyQ) Caenorhabditis elegans models, astragalan can reduce polyQ aggregation, alleviate neurotoxicity, and extend the adult lifespan, by regulating DAF-16 downstream genes such as scl-20, dct5, col-84, grd-4 and spp-20 [204].

\subsubsection{Protection against neurodegeneration and cognitive decline by Astragalan}

In an in vitro PD model of degenerate dopaminergic neurons induced by 6-Hydroxydopamine, astragalan demonstrated a protective effect against 6-OHDA neurotoxicity through alleviating the oxidative stress, inhibiting the apoptosis pathway by suppressing the proapoptotic gene egl-1 expression and increasing acetylcholinesterase activity [205].

\section{Special monomer extract from Astragalus membranaceus}

\subsection{TA-65}

TA-65, a single chemical entity isolated from the extract of the root of Astragalus membranaceus, leads to an improvement of certain health-span indicators including glucose tolerance, osteoporosis and skin fitness, without significantly increasing global cancer incidence in female mice [206].

\subsubsection{Anti-aging effect of TA-65}

Telomeres are essential genetic elements responsible for protecting chromosomes, and short telomeres are associated with aging and many diseases [207-209]. A number of studies have shown that activating telomerase can maintain telomere length, delay aging, and reverse age tissue degeneration [210,211]. TA-65 increased telomerase activity in a telomere shortening cell model IMR90 cells [212]. TA-65 can also lengthen the red blood cell telomere lengths and produce higher rates of feather renewal in captive zebra finches [213]. Consistent with this, TA-65 can activate telomerase to increase average telomere length in haploinsufficient mouse embryonic fibroblasts and aged mice, decrease the percentage of DNA damage and remodel the relative proportions of circulating leukocytes, reduce the percentage of cells with short telomeres and improve the structure of multiple tissues, at the same time. In old female mice, TA-65 administration for 4 months enhanced the health span, but had no impact on mean or maximum longevity [206]. A randomized, double blind, placebo controlled clinical research involving 117 relatively healthy cytomegalovirus-positive subjects aged 53-87 years old found that TA-65 can lengthen telomeres [214]. A study enrolling 7000 person-years in over a 5-year period, found that TA-65 improves markers of metabolic, bone, and cardiovascular health, with no adverse events, which suggests that TA-65 improves health and may reduce risk of morbidity and mortality [215].

\subsubsection{Immunoregulation by TA-65}

In human bodies, TA-65 exerts positive immune remodeling effects, including significant declines in the percent of senescent cytotoxic $\mathrm{T}$ cells and natural killer cells, particularly in cytomegalovirus-seropositive subjects over a 1 -year period relative to baseline values [216]. In cultured human CD4 and CD8 T cells from six healthy donors, it was found that TA-65 increased the telomerase activity by regulating the MAPK-specific pathway and increased proliferative activity [217].

\subsection{TAT2}

TAT2 is a single chemical entity isolated from the extract of the root of Astragalus membranaceus.

\subsubsection{Immunoregulation by TAT2}

In tissue culture studies with $\mathrm{CD} 8+\mathrm{T}$ cells from HIV/acquired immunodeficiency syndrome subjects, TAT2 increased replicative capacity, improved cytokine and chemokine responses to antigens, increased killing of autologous HIV-infected CD4+ cells, and retarded 
telomere shortening by regulating telomerase at the transcription level, probably through the regulation of the MAPK pathway [86]. And TAT2/cycloastragenol could implicate activation of c-Src, MEK, and epidermal growth factor receptor by inhibitor studies [86].

\section{Conclusion}

In this review, the current state of Astragalus membranaceus research involving aging and agingrelated diseases is detailed and elucidated. Astragalus membranaceus has multiple pharmacological effects, including anti-oxidative-stress, anti-inflammatory, immuno-regulation, vascular protective effects, antineurodegeneration, anti-cancer and anti-aging effects via numerous signaling pathways in vital organs and systems. More attention and further studies are needed to evaluate the underlying mechanisms of Astragalus membranaceus actions and its targets, in particular, reveal the mechanisms of its metabolism of absorption, distribution, transformation, and excretion. Based on the existing studies and clinical practices, Astragalus membranaceus has a good potential for broad application in aging and aging-related diseases.

Astragalus is usually taken in combination with other herbal supplements. When used appropriately, astragalus appears to be very safe and to have few side effects. Very high doses may suppress the immune system. Hence patients should avoid using astragalus if they are taking immune-suppressing drugs. Pregnant or nursing women should not use the astragalus root. If a person has an immune system disease, such as multiple sclerosis, lupus, rheumatoid arthritis, or another condition known as an "autoimmune disease," that person should not use the astragalus root. As with any herbal supplement, it is always necessary to check with an appropriate health care provider before taking the astragalus root.

The appropriate dose of astragalus depends on several factors, such as the user's age, health status, and several other conditions. At this time, there is not yet enough scientific information to determine an appropriate range of doses for astragalus. It is necessary to keep in mind that natural products are not always necessarily safe, and dosages can be important. It is important to follow relevant directions on product labels and consult the personal pharmacist or physician or other healthcare professional before use.

\section{Conflict of Interests}

The authors declare that there is no conflict of interest regarding the publication of this paper.

\section{Acknowledgments}

This project was supported by the Natural Science Foundation in China $(81471340,81601157)$, Beijing Nova Program (Z151100000315065).

\section{References}

[1] Flatt T (2012). A new definition of aging? Front Genet, 3: 148 .

[2] Shay JW (2016). Role of Telomeres and Telomerase in Aging and Cancer. Cancer Discov, 6: 584-593.

[3] Sen P, Shah PP, Nativio R, Berger SL (2016). Epigenetic Mechanisms of Longevity and Aging. Cell, 166: 822-839.

[4] Lu Y, Biancotto A, Cheung F, Remmers E, Shah N, McCoy JP, et al. (2016). Systematic Analysis of Cellto-Cell Expression Variation of $\mathrm{T}$ Lymphocytes in a Human Cohort Identifies Aging and Genetic Associations. Immunity, 45: 1162-1175.

[5] Goodell MA, Rando TA (2015). Stem cells and healthy aging. Science, 350: 1199-1204.

[6] Wang Y, Hekimi S (2015). Mitochondrial dysfunction and longevity in animals: Untangling the knot. Science, 350: 1204-1207.

[7] Finkel $\mathrm{T}$ (2015). The metabolic regulation of aging. Nat Med, 21:1416-1423.

[8] Cancro MP, Hao Y, Scholz JL, Riley RL, Frasca D, Dunn-Walters DK, et al. (2009). B cells and aging: molecules and mechanisms. Trends Immunol, 30: 313318.

[9] Kaushik S, Cuervo AM (2015). Proteostasis and aging. Nat Med, 21: 1406-1415.

[10] Biagi E, Franceschi C, Rampelli S, Severgnini M, Ostan R, Turroni S, et al. (2016). Gut Microbiota and Extreme Longevity. Curr Biol, 26:1480-1485.

[11] Auyeung KK, Han QB, Ko JK (2016). Astragalus membranaceus: A Review of its Protection Against Inflammation and Gastrointestinal Cancers. Am J Chin Med, 44: 1-22.

[12] Hei ZQ, Huang HQ, Zhang JJ, Chen BX, Li XY (2005). Protective effect of Astragalus membranaceus on intestinal mucosa reperfusion injury after hemorrhagic shock in rats. World J Gastroenterol, 11: 4986-4991.

[13] Ma J, Qiao Z, Xiang X (2011). Aqueous extract of Astragalus mongholicus ameliorates high cholesterol diet induced oxidative injury in experimental rat models. J Med Plant Res, 5:855-858.

[14] Ryu M, Kim EH, Chun M, Kang S, Shim B, Yu YB, et al. (2008). Astragali Radix elicits anti-inflammation via activation of MKP-1, concomitant with attenuation of p38 and Erk. J Ethnopharmacol, 115: 184-193.

Zhu H, Zhang Y, Ye G, Li Z, Zhou P, Huang C (2009). In vivo and in vitro antiviral activities of calycosin-7O-beta-D-glucopyranoside against coxsackie virus B3. Biol Pharm Bull, 32: 68-73.

[16] Chan JY, Lam F, Leung P, Che C, Fung K (2009). Antihyperglycemic and antioxidative effects of an 
herbal formulation of radix astragali, radix codonopsis and cortex lycii in a mouse model of type 2 diabetes mellitus. Phytother Res, 23: 658-665.

[17] Nalbantsoy A, Nesil T, Yilmaz-Dilsiz O, Aksu G, Khan S, Bedir E (2012). Evaluation of the immunomodulatory properties in mice and in vitro anti-inflammatory activity of cycloartane type saponins from Astragalus species. J Ethnopharmacol, 139: 574-581.

[18] Anon (2003). Astragalus membranaceus. Monograph. Altern Med Rev, 8: 72-77.

[19] Shahzad M, Shabbir A, Wojcikowski K, Wohlmuth H, Gobe GC (2016). The Antioxidant Effects of Radix Astragali (Astragalus membranaceus and Related Species) in Protecting Tissues from Injury and Disease. Curr Drug Targets, 17:1331-1340.

[20] Hong $\mathrm{CY}, \mathrm{Ku} \mathrm{J}, \mathrm{Wu} \mathrm{P}$ (1992). Astragalus membranaceus stimulates human sperm motility in vitro. Am J Chin Med, 20: 289-294.

[21] Zhang K, Pugliese M, Pugliese A, Passantino A (2015). Biological active ingredients of traditional Chinese herb Astragalus membranaceus on treatment of diabetes: a systematic review. Mini Rev Med Chem, 15:315-329.

[22] Li X, Qu L, Dong Y, Han L, Liu E, Fang S, et al. (2014). A review of recent research progress on the astragalus genus. Molecules, 19: 18850-18880.

[23] Qi LW, Yu QT, Yi L, Ren MT, Wen XD, Wang YX, et al. (2008). Simultaneous determination of 15 marker constituents in various radix Astragali preparations by solid-phase extraction and high-performance liquid chromatography. J Sep Sci, 31: 97-106.

[24] Song JZ, Mo SF, Yip YK, Qiao CF, Han QB, Xu HX (2007). Development of microwave assisted extraction for the simultaneous determination of isoflavonoids and saponins in radix astragali by high performance liquid chromatography. J Sep Sci, 30: 819-824.

[25] Fu J, Wang Z, Huang L, Zheng S, Wang D, Chen S, et al. (2014). Review of the botanical characteristics, phytochemistry, and pharmacology of Astragalus membranaceus (Huangqi). Phytother Res, 28: 12751283.

[26] Jin M, Zhao K, Huang Q, Shang P (2014). Structural features and biological activities of the polysaccharides from Astragalus membranaceus. Int J Biol Macromol, 64:257-266.

[27] Ma X, Zhang K, Li H, Han S, Ma Z, Tu P (2013). Extracts from Astragalus membranaceus limit myocardial cell death and improve cardiac function in a rat model of myocardial ischemia. J Ethnopharmacol, 149: 720-728.

[28] Cao J, Chen Z, Zhu Y, Li Y, Guo C, Gao K, et al. (2014). Huangqi-Honghua combination and its main components ameliorate cerebral infarction with Qi deficiency and blood stasis syndrome by antioxidant action in rats. J Ethnopharmacol, 155: 1053-1060.

[29] (2003). Astragalus membranaceus. Monograph. Altern Med Rev, 8: 72-77.

[30] Ragupathi G, Yeung KS, Leung P, Lee M, Lau CBS,
Vickers A, et al. (2008). Evaluation of widely consumed botanicals as immunological adjuvants. Vaccine, 26: 4860-4865.

[31] Denzler KL, Waters R, Jacobs BL, Rochon Y, Langland JO (2010). Regulation of inflammatory gene expression in PBMCs by immunostimulatory botanicals. PLoS One, 5: e12561.

[32] Lee YS, Han OK, Park CW, Yang CH, Jeon TW, Yoo WK, et al. (2005). Pro-inflammatory cytokine gene expression and nitric oxide regulation of aqueous extracted Astragali radix in RAW 264.7 macrophage cells. J Ethnopharmacol, 100: 289-294.

[33] Qin Q, Niu J, Wang Z, Xu W, Qiao Z, Gu Y (2012). Astragalus membranaceus inhibits inflammation via phospho-P38 mitogen-activated protein kinase (MAPK) and nuclear factor (NF)-kappaB pathways in advanced glycation end product-stimulated macrophages. Int J Mol Sci, 13: 8379-8387.

[34] Cho WC, Leung KN (2007). In vitro and in vivo immunomodulating and immunorestorative effects of Astragalus membranaceus. J Ethnopharmacol, 113: 132-141.

[35] Zwickey H, Brush J, Iacullo CM, Connelly E, Gregory WL, Soumyanath A, et al. (2007). The effect of Echinacea purpurea, Astragalus membranaceus and Glycyrrhiza glabra on CD25 expression in humans: a pilot study. Phytother Res, 21: 1109-1112.

[36] Brush J, Mendenhall E, Guggenheim A, Chan T, Connelly E, Soumyanath A, et al. (2006). The effect of Echinacea purpurea, Astragalus membranaceus and Glycyrrhiza glabra on CD69 expression and immune cell activation in humans. Phytother Res, 20: 687-695.

[37] Kang H, Ahn KS, Cho C, Bae HS (2004). Immunomodulatory effect of Astragali Radix extract on murine TH1/TH2 cell lineage development. Biol Pharm Bull, 27: 1946-1950.

[38] Mao S, Cheng K, Zhou Y (2004). Modulatory effect of Astragalus membranaceus on Th1/Th2 cytokine in patients with herpes simplex keratitis. Zhongguo Zhong Xi Yi Jie He Za Zhi, 24: 121-123.

[39] Ghafourian BM, Azemi ME, Hemmati AA, Taghian A, Azadmehr A (2011). Immunomodulatory effects of Astragalus gypsicolus hydroalcoholic extract in ovalbumin-induced allergic mice model. Iran $\mathbf{J}$ Allergy Asthma Immunol, 10: 281-288.

[40] Zhu X, Zhu B (2007). Mechanisms by which Astragalus membranaceus injection regulates hematopoiesis in myelosuppressed mice. Phytother Res, 21: 663-667.

[41] Shi R, He L, Hu Y, Yi N, Weng S, Cao Y (2001). The regulatory action of Radix Astragali on M-cholinergic receptor of the brain of senile rats. J Tradit Chin Med, 21:232-235.

[42] Tohda C, Tamura T, Matsuyama S, Komatsu K (2006). Promotion of axonal maturation and prevention of memory loss in mice by extracts of Astragalus mongholicus. Br J Pharmacol, 149: 532-541.

[43] Cho WC, Leung KN (2007). In vitro and in vivo antitumor effects of Astragalus membranaceus. Cancer 
Lett, 252: 43-54.

[44] Liu X, Yang Y, Zhang X, Xu S, He S, Huang W, et al. (2010). Compound Astragalus and Salvia miltiorrhiza extract inhibits cell invasion by modulating transforming growth factor-beta/Smad in HepG2 cell. J Gastroenterol Hepatol, 25: 420-426.

[45] Rui W, Xie L, Liu X, He S, Wu C, Zhang X, et al. (2014). Compound Astragalus and Salvia miltiorrhiza extract suppresses hepatocellular carcinoma progression by inhibiting fibrosis and PAI-1 mRNA transcription. J Ethnopharmacol, 151: 198-209.

[46] Cui R, He J, Wang B, Zhang F, Chen G, Yin S, et al. (2003). Suppressive effect of Astragalus membranaceus Bunge on chemical hepatocarcinogenesis in rats. Cancer Chemother Pharmacol, 51: 75-80.

[47] Lin J, Dong HF, Oppenheim JJ, Howard OM (2003). Effects of astragali radix on the growth of different cancer cell lines. World J Gastroenterol, 9: 670-673.

[48] Na D, Liu FN, Miao ZF, Du ZM, Xu HM (2009). Astragalus extract inhibits destruction of gastric cancer cells to mesothelial cells by anti-apoptosis. World J Gastroenterol, 15: 570-577.

[49] McCulloch M, See C, Shu XJ, Broffman M, Kramer A, Fan WY, et al. (2006). Astragalus-based Chinese herbs and platinum-based chemotherapy for advanced non-small-cell lung cancer: meta-analysis of randomized trials. J Clin Oncol, 24: 419-430.

[50] Lau BH, Ruckle HC, Botolazzo T, Lui PD (1994). Chinese medicinal herbs inhibit growth of murine renal cell carcinoma. Cancer Biother, 9: 153-161.

[51] Kurashige S, Akuzawa Y, Endo F (1999). Effects of astragali radix extract on carcinogenesis, cytokine production, and cytotoxicity in mice treated with a carcinogen, N-butyl-N'-butanolnitrosoamine. Cancer Invest, 17: 30-35.

[52] Wang Y, Ren T, Zheng L, Chen H, Ko JK, Auyeung KK (2016). Astragalus saponins inhibits lipopolysaccharide-induced inflammation in mouse macrophages. Am J Chin Med, 44: 579-593.

[53] Liu QS, Wang HF, Sun AK, Huo XP, Liu JL, Ma SH, et al. (2014). A comparative study on inhibition of total astragalus saponins and astragaloside IV on TNFR1mediated signaling pathways in arterial endothelial cells. PLoS One, 9: e101504.

[54] Wang T, Xuan X, Li M, Gao P, Zheng Y, Zang W, et al. (2013). Astragalus saponins affect proliferation, invasion and apoptosis of gastric cancer BGC-823 cells. Diagn Pathol, 8: 179.

[55] Tin MM, Cho CH, Chan K, James AE, Ko JK (2007). Astragalus saponins induce growth inhibition and apoptosis in human colon cancer cells and tumor xenograft. Carcinogenesis, 28: 1347-1355.

[56] Auyeung KK, Cho CH, Ko JK (2009). A novel anticancer effect of Astragalus saponins: transcriptional activation of NSAID-activated gene. Int J Cancer, 125: 1082-1091.

[57] Auyeung KK, Mok NL, Wong CM, Cho CH, Ko JK (2010). Astragalus saponins modulate mTOR and
ERK signaling to promote apoptosis through the extrinsic pathway in HT-29 colon cancer cells. Int J Mol Med, 26:341-349.

[58] Auyeung KK, Woo PK, Law PC, Ko JK (2012). Astragalus saponins modulate cell invasiveness and angiogenesis in human gastric adenocarcinoma cells. $\mathrm{J}$ Ethnopharmacol, 141: 635-641.

[59] Auyeung KK, Law PC, Ko JK (2009). Astragalus saponins induce apoptosis via an ERK-independent NF-kappaB signaling pathway in the human hepatocellular HepG2 cell line. Int J Mol Med, 23:189196.

[60] Law PC, Auyeung KK, Chan LY, Ko JK (2012). Astragalus saponins downregulate vascular endothelial growth factor under cobalt chloridestimulated hypoxia in colon cancer cells. BMC Complement Altern Med, 12: 160.

[61] Wang Y, Auyeung KK, Zhang X, Ko JK (2014). Astragalus saponins modulates colon cancer development by regulating calpain-mediated glucoseregulated protein expression. BMC Complement Altern Med,14:401.

[62] Li WZ, Li WP, Yin YY (2007). Effects of AST and ASI on metabolism of free radical in senescent rats treated by HC. Zhongguo Zhong Yao Za Zhi, 32: 2539-2542.

[63] Lei H, Wang B, Li WP, Yang Y, Zhou AW, Chen MZ (2003). Anti-aging effect of astragalosides and its mechanism of action. Acta Pharmacol Sin, 24: 230234.

[64] Liu X, Min W (2011). Protective effects of astragaloside against ultraviolet A-induced photoaging in human fibroblasts. Zhong Xi Yi Jie He Xue Bao, 9: 328-332.

[65] Kong X, Hu Y, Rui R, Wang D, Li X (2004). Effects of Chinese herbal medicinal ingredients on peripheral lymphocyte proliferation and serum antibody titer after vaccination in chicken. Int Immunopharmacol, 4: 975-982.

[66] Wan CP, Gao LX, Hou LF, Yang XQ, He PL, Yang YF, et al. (2013). Astragaloside II triggers $T$ cell activation through regulation of CD45 protein tyrosine phosphatase activity. Acta Pharmacol Sin, 34: 522-530.

[67] Yu JM, Zhang XB, Jiang W, Wang HD, Zhang YN (2015). Astragalosides promote angiogenesis via vascular endothelial growth factor and basic fibroblast growth factor in a rat model of myocardial infarction. Mol Med Rep, 12: 6718-6726.

[68] Hu XY, Xia RX, Cheng CB, Yang MZ, Zeng QS, Xia $\mathrm{HL}$, et al. (2011). Mechanism of apoptosis in human leukemia NB4 cells induced by total astragalosides. Zhonghua Zhong Liu Za Zhi, 33: 345-348.

[69] Meng D, Chen XJ, Bian YY, Li P, Yang D, Zhang JN (2005). Effect of astragalosides on intracellular calcium overload in cultured cardiac myocytes of neonatal rats. Am J Chin Med, 33: 11-20.

[70] Yin YY, Li WP, Gong HL, Zhu FF, Li WZ, Wu GC (2010). Protective effect of astragaloside on focal cerebral ischemia/reperfusion injury in rats. Am J Chin 
Med, 38: 517-527.

[71] Chiu BY, Chang CP, Lin JW, Yu JS, Liu WP, Hsu YC, et al. (2014). Beneficial effect of astragalosides on stroke condition using PC12 cells under oxygen glucose deprivation and reperfusion. Cell Mol Neurobiol, 34: 825-837.

[72] Li WZ, Wu WY, Huang DK, Yin YY, Kan HW, Wang $\mathrm{X}$, et al. (2012). Protective effects of astragalosides on dexamethasone and Abeta25-35 induced learning and memory impairments due to decrease amyloid precursor protein expression in 12-month male rats. Food Chem Toxicol, 50: 1883-1890.

[73] Chang CP, Liu YF, Lin HJ, Hsu CC, Cheng BC, Liu WP, et al. (2016). Beneficial Effect of Astragaloside on Alzheimer's Disease Condition Using Cultured Primary Cortical Cells Under beta-amyloid Exposure. Mol Neurobiol, 53: 7329-7340.

[74] Wu YY, Wu WY, Gong HL, Li WZ, Yin YY (2014). Astragalosides attenuate learning and memory impairment in rats following ischemiareperfusion injury. Mol Med Rep, 9: 1319-1324.

[75] OuYang Y, Huang J, OuYang Z, Kang J (2014). Enrichment and purification process of astragalosides and their anti-human gastric cancer MKN-74 cell proliferation effect. Afr Health Sci, 14: 22-27.

[76] Hong F, Xiao W, Ragupathi G, Lau CB, Leung PC, Yeung KS, et al. (2011). The known immunologically active components of Astragalus account for only a small proportion of the immunological adjuvant activity when combined with conjugate vaccines. Planta Med, 77: 817-824.

[77] Wang M, Huang C, Su Y, Yang C, Xia Q, Xu DJ (2017). Astragaloside II sensitizes human hepatocellular carcinoma cells to 5-fluorouracil via suppression of autophagy. J Pharm Pharmacol, 69: 743-752.

[78] Huang C, Xu D, Xia Q, Wang P, Rong C, Su Y (2012). Reversal of P-glycoprotein-mediated multidrug resistance of human hepatic cancer cells by Astragaloside II. J Pharm Pharmacol, 64: 1741-1750.

[79] Zhang Q, Zhu LL, Chen GG, Du Y (2007). Pharmacokinetics of astragaloside iv in beagle dogs. Eur J Drug Metab Pharmacokinet, 32: 75-79.

[80] Huang CR, Wang GJ, Wu XL, Li H, Xie HT, Lv H, et al. (2006). Absorption enhancement study of astragaloside IV based on its transport mechanism in caco-2 cells. Eur J Drug Metab Pharmacokinet, 31: 510.

[81] Yang B, Ji C, Chen X, Cui L, Bi Z, Wan Y, et al. (2011). Protective effect of astragaloside IV against matrix metalloproteinase-1 expression in ultravioletirradiated human dermal fibroblasts. Arch Pharm Res, 34: 1553-1560.

[82] Chen B, Li R, Yan N, Chen G, Qian W, Jiang HL, et al. (2015). Astragaloside IV controls collagen reduction in photoaging skin by improving transforming growth factor-beta/Smad signaling suppression and inhibiting matrix metalloproteinase-1. Mol Med Rep, 11: 3344-3348.
Wang YP, Li XY, Song CQ, Hu ZB (2002). Effect of astragaloside IV on T, B lymphocyte proliferation and peritoneal macrophage function in mice. Acta Pharmacol Sin, 23: 263-266.

[84] Li J, Huang L, Wang S, Yao Y, Zhang Z (2016). Astragaloside IV attenuates inflammatory reaction via activating immune function of regulatory T-cells inhibited by HMGB1 in mice. Pharm Biol, 54: 32173225 .

[85] Huang LF, Yao YM, Li JF, Zhang SW, Li WX, Dong $\mathrm{N}$, et al. (2012). The effect of Astragaloside IV on immune function of regulatory $\mathrm{T}$ cell mediated by high mobility group box 1 protein in vitro. Fitoterapia, 83: 1514-1522.

[86] Fauce SR, Jamieson BD, Chin AC, Mitsuyasu RT, Parish ST, Ng HL, et al. (2008). Telomerase-based pharmacologic enhancement of antiviral function of human CD8+ T lymphocytes. J Immunol, 181: 74007406.

[87] Yung LY, Lam WS, Ho MK, Hu Y, Ip FC, Pang H, et al. (2012). Astragaloside IV and cycloastragenol stimulate the phosphorylation of extracellular signalregulated protein kinase in multiple cell types. Planta Med, 78: 115-121.

[88] Zhang WJ, Hufnagl P, Binder BR, Wojta J (2003). Antiinflammatory activity of astragaloside IV is mediated by inhibition of NF-kappaB activation and adhesion molecule expression. Thromb Haemost, 90: 904-914.

[89] Cheng S, Yu P, Yang L, Shi H, He A, Chen H, et al. (2016). Astragaloside IV enhances cardioprotection of remote ischemic conditioning after acute myocardial infarction in rats. Am J Transl Res, 8: 4657-4669.

[90] Hu JY, Han J, Chu ZG, Song HP, Zhang DX, Zhang $\mathrm{Q}$, et al. (2009). Astragaloside IV attenuates hypoxiainduced cardiomyocyte damage in rats by upregulating superoxide dismutase-1 levels. Clin Exp Pharmacol Physiol, 36: 351-357.

[91] Huang H, Lai S, Wan Q, Qi W, Liu J (2016). Astragaloside IV protects cardiomyocytes from anoxia/reoxygenation injury by upregulating the expression of Hes1 protein. Can J Physiol Pharmacol, 94: 542-553.

[92] Wang C, Li Y, Yang X, Bi S, Zhang Y, Han D, et al. (2017). Tetramethylpyrazine and Astragaloside IV Synergistically Ameliorate Left Ventricular Remodeling and Preserve Cardiac Function in a Rat Myocardial Infarction Model. J Cardiovasc Pharmacol, 69: 34-40.

[93] Yang J, Wang HX, Zhang YJ, Yang YH, Lu ML, Zhang J, et al. (2013). Astragaloside IV attenuates inflammatory cytokines by inhibiting TLR4/NF-small $\mathrm{ka}$, CyrillicB signaling pathway in isoproterenolinduced myocardial hypertrophy. J Ethnopharmacol, 150: 1062-1070.

[94] Cao YL, Chen CF, Wang AW, Feng YB, Cheng HX, Zhang WW, et al. (2015). Changes of peripheral-type benzodiazepine receptors in the penumbra area after cerebral ischemia-reperfusion injury and effects of 
astragaloside IV on rats. Genet Mol Res, 14: 277-285.

[95] Yang J, Li J, Lu J, Zhang Y, Zhu Z, Wan H (2012). Synergistic protective effect of astragaloside IVtetramethylpyrazine against cerebral ischemicreperfusion injury induced by transient focal ischemia. J Ethnopharmacol, 140: 64-72.

[96] Luo Y, Qin Z, Hong Z, Zhang X, Ding D, Fu JH, et al. (2004). Astragaloside IV protects against ischemic brain injury in a murine model of transient focal ischemia. Neurosci Lett, 363: 218-223.

[97] Huang XP, Qiu YY, Wang B, Ding H, Tang YH, Zeng $R$, et al. (2014). Effects of Astragaloside IV combined with the active components of Panax notoginseng on oxidative stress injury and nuclear factor-erythroid 2related factor $2 /$ heme oxygenase- 1 signaling pathway after cerebral ischemia-reperfusion in mice. Pharmacogn Mag, 10: 402-409.

[98] Gu DM, Lu PH, Zhang K, Wang X, Sun M, Chen GQ, et al. (2015). EGFR mediates astragaloside IV-induced Nrf2 activation to protect cortical neurons against in vitro ischemia/reperfusion damages. Biochem Biophys Res Commun, 457: 391-397.

[99] Li M, Qu YZ, Zhao ZW, Wu SX, Liu YY, Wei XY, et al. (2012). Astragaloside IV protects against focal cerebral ischemia/reperfusion injury correlating to suppression of neutrophils adhesion-related molecules. Neurochem Int, 60: 458-465.

[100] Wang SG, Xu Y, Chen JD, Yang CH, Chen XH (2013). Astragaloside IV stimulates angiogenesis and increases nitric oxide accumulation via JAK2/STAT3 and ERK1/2 pathway. Molecules, 18: 12809-12819.

[101] Zhang Y, Hu G, Li S, Li ZH, Lam CO, Hong SJ, et al. (2012). Pro-angiogenic activity of astragaloside IV in HUVECs in vitro and zebrafish in vivo. Mol Med Rep, 5: 805-811.

[102] Xu C, Tang F, Lu M, Yang J, Han R, Mei M, et al. (2016). Pretreatment with Astragaloside IV protects human umbilical vein endothelial cells from hydrogen peroxide induced oxidative stress and cell dysfunction via inhibiting eNOS uncoupling and NADPH oxidase - ROS - NF-kappaB pathway. Can J Physiol Pharmacol, 30:1-9.

[103] Chen Z, Cai Y, Zhang W, Liu X, Liu S (2014). Astragaloside IV inhibits platelet-derived growth factor-BB-stimulated proliferation and migration of vascular smooth muscle cells via the inhibition of $\mathrm{p} 38$ MAPK signaling. Exp Ther Med, 8: 1253-1258.

[104] Wang X, Wang Y, Hu JP, Yu S, Li BK, Cui Y, et al. (2017). Astragaloside IV, a Natural PPARgamma Agonist, Reduces Abeta Production in Alzheimer's Disease Through Inhibition of BACE1. Mol Neurobiol, 54: 2939-2949.

[105] Sun Q, Jia N, Wang W, Jin H, Xu J, Hu H (2014). Protective effects of astragaloside IV against amyloid beta1-42 neurotoxicity by inhibiting the mitochondrial permeability transition pore opening. PLoS One, 9: e98866.

[106] Kim S, Kang IH, Nam JB, Cho Y, Chung DY, Kim SH, et al. (2015). Ameliorating the effect of astragaloside
IV on learning and memory deficit after chronic cerebral hypoperfusion in rats. Molecules, 20: 19041921.

[107] Li M, Li H, Fang F, Deng X, Ma S (2017). Astragaloside IV attenuates cognitive impairments induced by transient cerebral ischemia and reperfusion in mice via anti-inflammatory mechanisms. Neurosci Lett, 639: 114-119.

[108] Haiyan H, Rensong Y, Guoqin J, Xueli Z, Huaying X, Yanwu X (2016). Effect of astragaloside iv on neural stem cell transplantation in alzheimer's disease rat models. Evid Based Complement Alternat Med, 2016: 3106980.

[109] Chan WS, Durairajan SS, Lu JH, Wang Y, Xie LX, Kum WF, et al. (2009). Neuroprotective effects of Astragaloside IV in 6-hydroxydopamine-treated primary nigral cell culture. Neurochem Int, 55: 414422.

[110] Zhang ZG, Wu L, Wang JL, Yang JD, Zhang J, Zhang J, et al. (2012). Astragaloside IV prevents MPP(+)induced SH-SY5Y cell death via the inhibition of Baxmediated pathways and ROS production. Mol Cell Biochem, 364: 209-216.

[111] Liu HS, Shi HL, Huang F, Peterson KE, Wu H, Lan YY, et al. (2016). Astragaloside IV inhibits microglia activation via glucocorticoid receptor mediated signaling pathway. Sci Rep, 6: 19137.

[112] Qi H, Wei L, Han Y, Zhang Q, Lau AS, Rong J (2010). Proteomic characterization of the cellular response to chemopreventive triterpenoid astragaloside IV in human hepatocellular carcinoma cell line HepG2. Int J Oncol, 36: 725-735.

[113] Qin CD, Ma DN, Ren ZG, Zhu XD, Wang CH, Wang YC, et al. (2017). Astragaloside IV inhibits metastasis in hepatoma cells through the suppression of epithelial-mesenchymal transition via the Akt/GSK3beta/beta-catenin pathway. Oncol Rep, 37: 17251735

[114] Zhang S, Tang D, Zang W, Yin G, Dai J, Sun YU, et al. (2017). Synergistic inhibitory effect of traditional chinese medicine astragaloside iv and curcumin on tumor growth and angiogenesis in an orthotopic nudemouse model of human hepatocellular carcinoma. Anticancer Res, 37: 465-473.

[115] Zhang A, Zheng Y, Que Z, Zhang L, Lin S, Le V, et al. (2014). Astragaloside IV inhibits progression of lung cancer by mediating immune function of Tregs and CTLs by interfering with IDO. J Cancer Res Clin Oncol, 140: 1883-1890.

[116] Cheng X, Gu J, Zhang M, Yuan J, Zhao B, Jiang J, et al. (2014). Astragaloside IV inhibits migration and invasion in human lung cancer A549 cells via regulating PKC-alpha-ERK1/2-NF-kappaB pathway. Int Immunopharmacol, 23: 304-313.

[117] Jiang K, Lu Q, Li Q, Ji Y, Chen W, Xue X (2017). Astragaloside IV inhibits breast cancer cell invasion by suppressing Vav3 mediated Rac1/MAPK signaling. Int Immunopharmacol, 42: 195-202.

[118] Xie T, Li Y, Li SL, Luo HF (2016). Astragaloside IV 
enhances cisplatin chemosensitivity in human colorectal cancer via regulating NOTCH3. Oncol Res, 24: 447-453.

[119] He CS, Liu YC, Xu ZP, Dai PC, Chen XW, Jin DH (2016). Astragaloside IV Enhances Cisplatin Chemosensitivity in Non-Small Cell Lung Cancer Cells Through Inhibition of B7-H3. Cell Physiol Biochem, 40: 1221-1229.

[120] Kuo YH, Tsai WJ, Loke SH, Wu TS, Chiou WF (2009). Astragalus membranaceus flavonoids (AMF) ameliorate chronic fatigue syndrome induced by food intake restriction plus forced swimming. J Ethnopharmacol, 122: 28-34.

[121] Han R, Wu WQ, Wu XP, Liu CY (2015). Effect of total flavonoids from the seeds of Astragali complanati on natural killer cell function. J Ethnopharmacol, 173: 157-165.

[122] Li W, Sun YN, Yan XT, Yang SY, Kim S, Lee YM, et al. (2014). Flavonoids from Astragalus membranaceus and their inhibitory effects on LPS-stimulated proinflammatory cytokine production in bone marrowderived dendritic cells. Arch Pharm Res, 37: 186-192.

[123] Zhang LJ, Liu HK, Hsiao PC, Kuo LM, Lee IJ, Wu TS, et al. (2011). New isoflavonoid glycosides and related constituents from astragali radix (Astragalus membranaceus) and their inhibitory activity on nitric oxide production. J Agric Food Chem, 59: 1131-1137.

[124] Chen HJ, Chung CP, Chiang W, Lin YL (2011). Antiinflammatory effects and chemical study of a flavonoid-enriched fraction from adlay bran. Food Chem, 126:1741-1748.

[125] Lai PK, Chan JY, Cheng L, Lau CP, Han SQ, Leung PC, et al. (2013). Isolation of anti-inflammatory fractions and compounds from the root of Astragalus membranaceus. Phytother Res, 27: 581-587.

[126] Wang D, Zhuang Y, Tian Y, Thomas GN, Ying M, Tomlinson B (2012). Study of the effects of total flavonoids of Astragalus on atherosclerosis formation and potential mechanisms. Oxid Med Cell Longev, 2012: 282383.

[127] Wang D, Wang C, Tian Y (1999). Effect of total flavonoids of Astragalus on nitroxide in ischemia reperfusion injury. Zhongguo Zhong Xi Yi Jie He Za Zhi, 19: 221-223.

[128] Yu D, Duan Y, Bao Y, Wei C, An L (2005). Isoflavonoids from Astragalus mongholicus protect PC12 cells from toxicity induced by L-glutamate. J Ethnopharmacol, 98: 89-94.

[129] Arora A, Byrem TM, Nair MG, Strasburg GM (2000). Modulation of liposomal membrane fluidity by flavonoids and isoflavonoids. Arch Biochem Biophys, 373: 102-109.

[130] Mira L, Fernandez MT, Santos M, Rocha R, Florencio MH, Jennings KR (2002). Interactions of flavonoids with iron and copper ions: a mechanism for their antioxidant activity. Free Radic Res, 36: 1199-1208.

[131] Guo Q, Rimbach G, Moini H, Weber S, Packer L (2002). ESR and cell culture studies on free radicalscavenging and antioxidant activities of isoflavonoids.
Toxicology, 179: 171-180.

[132] Tian Z, Liu S, Wang Y, Li X, Zheng L, Zhao M (2013). Neuroprotective Effects of Formononetin Against NMDA-Induced Apoptosis in Cortical Neurons. Phytother Res, 27: 1770-1775.

[133] Hu Y, Liu C, Du C, Zhang J, Wu W, Gu Z (2009). Induction of apoptosis in human hepatocarcinoma SMMC-7721 cells in vitro by flavonoids from Astragalus complanatus. J Ethnopharmacol, 123: 293301.

[134] Saleem S, Shaharyar MA, Khusroo MJ, Ahmad P, Rahman RU, Ahmad K, et al. (2013). Anticancer potential of rhamnocitrin 4'-beta-D-galactopyranoside against N-diethylnitrosamine-induced hepatocellular carcinoma in rats. Mol Cell Biochem, 384: 147-153.

[135] Kondeva-Burdina M, Krasteva I, Mitcheva M (2014). Effects of rhamnocitrin 4-beta-D-galactopyranoside, isolated from Astragalus hamosus on toxicity models in vitro. Pharmacogn Mag, 10: S487-493.

[136] Yang MH, Kim J, Khan IA, Walker LA, Khan SI (2014). Nonsteroidal anti-inflammatory drug activated gene-1 (NAG-1) modulators from natural products as anti-cancer agents. Life Sci, 100: 75-84.

[137] Eling TE, Baek SJ, Shim M, Lee CH (2006). NSAID activated gene (NAG-1), a modulator of tumorigenesis. J Biochem Mol Biol, 39: 649-655.

[138] Buhagiar JA, Bertoli A, Camilleri-Podestac MT, Pistelli L (2008). In vitro apoptotic bioactivity of Flavonoids from Astragalus verrucosus Moris. Nat Prod Commun, 3: 2007-2012.

[139] Auyeung KK, Ko JK (2010). Novel herbal flavonoids promote apoptosis but differentially induce cell cycle arrest in human colon cancer cell. Invest New Drugs, 28: $1-13$

[140] Zhu J, Zhang H, Zhu Z, Zhang Q, Ma X, Cui Z, et al. (2015). Effects and mechanism of flavonoids from Astragalus complanatus on breast cancer growth. Naunyn Schmiedebergs Arch Pharmacol, 388: 965972.

[141] Zhang D, Zhuang Y, Pan J, Wang H, Li H, Yu Y, et al. (2012). Investigation of effects and mechanisms of total flavonoids of Astragalus and calycosin on human erythroleukemia cells. Oxid Med Cell Longev, 2012: 209843.

[142] Krasteva I, Momekov G, Zdraveva P, Konstantinov S, Nikolov S (2008). Antiproliferative effects of a flavonoid and saponins from Astragalus hamosus against human tumor cell lines. Pharmacogn Mag, 4: 269-272.

[143] Wang N, Liu J, Xie F, Gao X, Ye JH, Sun LY, et al. (2015). miR-124/ATF-6, a novel lifespan extension pathway of Astragalus polysaccharide in Caenorhabditis elegans. J Cell Biochem, 116: 242-251.

[144] Zhong L, Wang ZF, Wen DJ (2013). Experimental research on the anti-aging effects of astragalus polysaccharides. Zhongguo Ying Yong Sheng Li Xue Za Zhi, 29: 350-352.

[145] Li XT, Zhang YK, Kuang HX, Jin FX, Liu DW, Gao $\mathrm{MB}$, et al. (2012). Mitochondrial protection and anti- 
aging activity of Astragalus polysaccharides and their potential mechanism. Int J Mol Sci, 13: 1747-1761.

[146] Li R, Chen W, Wang W, Tian W, Zhang X (2010). Antioxidant activity of Astragalus polysaccharides and antitumour activity of the polysaccharides and siRNA. Carbohyd Polym, 82: 240-244.

[147] Yan H, Xie Y, Sun S, Sun X, Ren F, Shi Q, et al. (2010). Chemical analysis of Astragalus mongholicus polysaccharides and antioxidant activity of the polysaccharides. Carbohyd Polym, 82: 636-640.

[148] Jia R, Cao L, Xu P, Jeney G, Yin G (2012). In vitro and in vivo hepatoprotective and antioxidant effects of Astragalus polysaccharides against carbon tetrachloride-induced hepatocyte damage in common carp (Cyprinus carpio). Fish Physiol Biochem, 38: 871-881.

[149] Du X, Zhao B, Li J, Cao X, Diao M, Feng H, et al. (2012). Astragalus polysaccharides enhance immune responses of HBV DNA vaccination via promoting the dendritic cell maturation and suppressing Treg frequency in mice. Int Immunopharmacol, 14: 463470.

[150] Yuan C, Pan X, Gong Y, Xia A, Wu G, Tang J, et al. (2008). Effects of Astragalus polysaccharides (APS) on the expression of immune response genes in head kidney, gill and spleen of the common carp, Cyprinus carpio L. Int Immunopharmacol, 8: 51-58.

[151] Qiu H, Cheng G, Xu J, Zhang N, Liu F, Zhu X, et al. (2010). Effects of Astragalus Polysaccharides on Associated Immune Cells and Cytokines in Immunosuppressive Dogs. Procedia Vaccinol, 2: 2633.

[152] Guo L, Liu J, Hu Y, Wang D, Li Z, Zhang J, et al. (2012). Astragalus polysaccharide and sulfated epimedium polysaccharide synergistically resist the immunosuppression. Carbohydr Polym, 90:1055-1060.

[153] Lu Y, Xing QQ, Xu JY, Ding D, Zhao X (2016). Astragalus polysaccharide modulates ER stress response in an OVA-LPS induced murine model of severe asthma. Int J Biol Macromol, 93: 995-1006.

[154] Shao P, Zhao LH, Zhi-Chen, Pan JP (2006). Regulation on maturation and function of dendritic cells by Astragalus mongholicus polysaccharides. Int Immunopharmacol, 6: 1161-1166.

[155] Liu QY, Yao YM, Zhang SW, Sheng ZY (2011). Astragalus polysaccharides regulate $\mathrm{T}$ cell-mediated immunity via CD11c(high)CD45RB(low) DCs in vitro. J Ethnopharmacol, 136: 457-464.

[156] Liu QY, Yao YM, Yu Y, Dong N, Sheng ZY (2011). Astragalus polysaccharides attenuate postburn sepsis via inhibiting negative immunoregulation of $\mathrm{CD} 4+$ CD25(high) T cells. PLoS One, 6:e 19811.

[157] Hou YC, Wu JM, Wang MY, Wu MH, Chen KY, Yeh SL, et al. (2015). Modulatory Effects of Astragalus Polysaccharides on T-Cell Polarization in Mice with Polymicrobial Sepsis. Mediators Inflamm, 2015: 826319.

[158] Shao BM, Xu W, Dai H, Tu P, Li Z, Gao XM (2004). A study on the immune receptors for polysaccharides from the roots of Astragalus membranaceus, a Chinese medicinal herb. Biochem Biophys Res Commun, 320: 1103-1111.

[159] Wei W, Xiao HT, Bao WR, Ma DL, Leung CH, Han $X Q$, et al. (2016). TLR-4 may mediate signaling pathways of Astragalus polysaccharide RAP induced cytokine expression of RAW264.7 cells. J Ethnopharmacol, 179: 243-252.

[160] Lee KY, Jeon YJ (2005). Macrophage activation by polysaccharide isolated from Astragalus membranaceus. Int Immunopharmacol, 5: 1225-1233.

[161] Zhao LH, Ma ZX, Zhu J, Yu XH, Weng DP (2011). Characterization of polysaccharide from Astragalus radix as the macrophage stimulator. Cell Immunol, 271: 329-334.

[162] Wang J, Ito H, Shimura K (1989). Enhancing effect of antitumor polysaccharide from Astragalus or Radix hedysarum on $\mathrm{C} 3$ cleavage production of macrophages in mice. Jpn J Pharmacol, 51: 432-434.

[163] Wang Z, Liu Z, Zhou L, Long T, Zhou X, Bao Y (2017). Immunomodulatory effect of APS and PSP is mediated by Ca2+-cAMP and TLR4/NF-kappaB signaling pathway in macrophage. Int $\mathrm{J}$ Biol Macromol, 94: 283-289.

[164] He X, Shu J, Xu L, Lu C, Lu A (2012). Inhibitory effect of Astragalus polysaccharides on lipopolysaccharide-induced TNF-a and IL-1beta production in THP-1 cells. Molecules, 17: 3155-3164.

[165] Lu J, Chen X, Zhang Y, Xu J, Zhang L, Li Z, et al. (2013). Astragalus polysaccharide induces antiinflammatory effects dependent on AMPK activity in palmitate-treated RAW264.7 cells. Int J Mol Med, 31: 1463-1470.

[166] Fan Y, Hu Y, Wang D, Liu J, Zhang J, Zhao X, et al. (2012). Effects of Astragalus polysaccharide liposome on lymphocyte proliferation in vitro and adjuvanticity in vivo. Carbohyd Polym, 88: 68-74.

[167] Zhang N, Li J, Hu Y, Cheng G, Zhu X, Liu F, et al. (2010). Effects of astragalus polysaccharide on the immune response to foot-and-mouth disease vaccine in mice. Carbohyd Polym, 82: 680-686.

[168] Li J, Zhong Y, Li H, Zhang N, Ma W, Cheng G, et al. (2011). Enhancement of Astragalus polysaccharide on the immune responses in pigs inoculated with footand-mouth disease virus vaccine. Int J Biol Macromol, 49: 362-368.

[169] Zhu YP, Shen T, Lin YJ, Chen BD, Ruan Y, Cao Y, et al. (2013). Astragalus polysaccharides suppress ICAM-1 and VCAM-1 expression in TNF-alphatreated human vascular endothelial cells by blocking NF-kappaB activation. Acta Pharmacol Sin, 34: 10361042.

[170] Zhang X, Yao K, Ren L, Chen T, Yao D (2016). Protective effect of Astragalus polysaccharide on endothelial progenitor cells injured by thrombin. Int $\mathbf{J}$ Biol Macromol, 82: 711-718.

[171] Xie L, Wu Y, Fan Z, Liu Y, Zeng J (2016). Astragalus polysaccharide protects human cardiac microvascular endothelial cells from hypoxia/reoxygenation injury: 
The role of PI3K/AKT, Bax/Bcl-2 and caspase-3. Mol Med Rep, 14: 904-910.

[172] Wang YF, Yang XF, Cheng B, Mei CL, Li QX, Xiao $\mathrm{H}$, et al. (2010). Protective effect of Astragalus polysaccharides on ATP binding cassette transporter A1 in THP-1 derived foam cells exposed to tumor necrosis factor-alpha. Phytother Res, 24: 393-398.

[173] Cheng Y, Tang K, Wu S, Liu L, Qiang C, Lin X, et al. (2011). Astragalus polysaccharides lowers plasma cholesterol through mechanisms distinct from statins. PLoS One, 6: e27437.

[174] Tu S, Shao A, Ren L, Chen T, Yao D (2014). Angiogenesis effect of Astragalus polysaccharide combined with endothelial progenitor cells therapy in diabetic male rat following experimental hind limb ischemia. Chin Med J (Engl), 127: 2121-2128.

[175] Zhang H, Pan N, Xiong S, Zou S, Li H, Xiao L, et al. (2012). Inhibition of polyglutamine-mediated proteotoxicity by Astragalus membranaceus polysaccharide through the DAF-16/FOXO transcription factor in Caenorhabditis elegans. Biochem J, 441: 417-424.

[176] Dun C, Liu J, Qiu F, Wu X, Wang Y, Zhao Y, et al. (2016). Effects of Astragalus polysaccharides on memory impairment in a diabetic rat model. Neuropsychiatr Dis Treat, 12: 1617-1621.

[177] Luo T, Qin J, Liu M, Luo J, Ding F, Wang M, et al. (2015). Astragalus polysaccharide attenuates lipopolysaccharide-induced inflammatory responses in microglial cells: regulation of protein kinase B and nuclear factor-kappaB signaling. Inflamm Res, 64: 205-212.

[178] Ge L, Mao L, Tian JH, Shi FY, Lou L, Qiu X, et al. (2015). Network meta-analysis on selecting Chinese medical injections in radiotherapy for esophageal cancer. Zhongguo Zhong Yao Za Zhi, 40: 3674-3681.

[179] Wang JC, Tian JH, Ge L, Gan YH, Yang KH (2014). Which is the best Chinese herb injection based on the FOLFOX regimen for gastric cancer? A network meta- analysis of randomized controlled trials. Asian Pac J Cancer Prev, 15: 4795-4800.

[180] Li R, Chen W, Wang W, Tian W, Zhang X (2009). Extraction, characterization of Astragalus polysaccharides and its immune modulating activities in rats with gastric cancer. Carbohyd Polym, 78: 738742.

[181] Liu L, Zhang J, Li M, Zhang X, Zhang J, Li Z, et al. (2014). Inhibition of HepG2 cell proliferation by ursolic acid and polysaccharides via the downregulation of cyclooxygenase-2. Mol Med Rep, 9: 2505-2511.

[182] Luo C, Urgard E, Vooder T, Metspalu A (2011). The role of COX-2 and Nrf2/ARE in anti-inflammation and antioxidative stress: Aging and anti-aging. Med Hypotheses, 77: 174-178.

[183] Huang WH, Liao WR, Sun RX (2016). Astragalus polysaccharide induces the apoptosis of human hepatocellular carcinoma cells by decreasing the expression of Notch1. Int J Mol Med, 38: 551-557.
[184] Tian QE, Li HD, Yan M, Cai HL, Tan QY, Zhang WY (2012). Astragalus polysaccharides can regulate cytokine and P-glycoprotein expression in $\mathrm{H} 22$ tumorbearing mice. World J Gastroenterol, 18: 7079-7086.

[185] Lai X, Xia W, Wei J, Ding X (2017). Therapeutic Effect of Astragalus Polysaccharides on Hepatocellular Carcinoma H22-Bearing Mice. Dose Response, 15: 1559325816685182.

[186] Yang B, Xiao B, Sun T (2013). Antitumor and immunomodulatory activity of Astragalus membranaceus polysaccharides in $\mathrm{H} 22$ tumor-bearing mice. Int J Biol Macromol, 62: 287-290.

[187] Li Q, Bao JM, Li XL, Zhang T, Shen XH (2012). Inhibiting effect of Astragalus polysaccharides on the functions of CD4+CD25 highTreg cells in the tumor microenvironment of human hepatocellular carcinoma. Chin Med J (Engl), 125: 786-793.

[188] Sun S, Zheng K, Zhao H, Lu C, Liu B, Yu C, et al. (2014). Regulatory effect of astragalus polysaccharides on intestinal intraepithelial gammadeltaT cells of tumor bearing mice. Molecules, 19: 15224-15236.

[189] Li J, Bao Y, Lam W, Li W, Lu F, Zhu X, et al. (2008). Immunoregulatory and anti-tumor effects of polysaccharopeptide and Astragalus polysaccharides on tumor-bearing mice. Immunopharmacol Immunotoxicol, 30: 771-782.

[190] Zhou Z, Meng M, Ni H (2017). Chemosensitizing effect of astragalus polysaccharides on nasopharyngeal carcinoma cells by inducing apoptosis and modulating expression of bax/bcl-2 ratio and caspases. Med Sci Monit, 23: 462-469.

[191] Guo L, Bai SP, Zhao L, Wang XH (2012). Astragalus polysaccharide injection integrated with vinorelbine and cisplatin for patients with advanced non-small cell lung cancer: effects on quality of life and survival. Med Oncol, 29: 1656-1662.

[192] Zhang JX, Han YP, Bai C, Li Q (2015). Notch1/3 and p53/p21 are a potential therapeutic target for APSinduced apoptosis in non-small cell lung carcinoma cell lines. Int J Clin Exp Med, 8: 12539-12547.

[193] Ming H, Chen Y, Zhang F, Wang Q, Dong X, Gu J, et al. (2015). Astragalus polysaccharides combined with cisplatin decreases the serum levels of CD44 and collagen type IV and hyaluronic acid in mice bearing Lewis lung cancer. Xi Bao Yu Fen Zi Mian Yi Xue Za Zhi, 31: 909-913.

[194] Ye MN, Chen HF, Zhou RJ, Liao MJ (2011). Effects of Astragalus polysaccharide on proliferation and Akt phosphorylation of the basal-like breast cancer cell line. Zhong Xi Yi Jie He Xue Bao, 9: 1339-1346.

[195] Zhou L, Liu Z, Wang Z, Yu S, Long T, Zhou X, et al. (2017). Astragalus polysaccharides exerts immunomodulatory effects via TLR4-mediated MyD88-dependent signaling pathway in vitro and in vivo. Sci Rep, 7: 44822.

[196] Liu W, Gao FF, Li Q, Lv JW, Wang Y, Hu PC, et al. (2014). Protective effect of astragalus polysaccharides on liver injury induced by several different 
chemotherapeutics in mice. Asian Pac J Cancer Prev, 15: 10413-10420.

[197] Cao Y, Shen T, Huang X, Lin Y, Chen B, Pang J, et al. (2017). Astragalus polysaccharide restores autophagic flux and improves cardiomyocyte function in doxorubicin-induced cardiotoxicity. Oncotarget, 8: 4837-4848.

[198] Cao Y, Ruan Y, Shen T, Huang X, Li M, Yu W, et al. (2014). Astragalus polysaccharide suppresses doxorubicin-induced cardiotoxicity by regulating the PI3k/Akt and p38MAPK pathways. Oxid Med Cell Longev, 2014: 674219.

[199] Zhou L, Chen L, Wang J, Deng Y (2015). Astragalus polysaccharide improves cardiac function in doxorubicin-induced cardiomyopathy through ROSp38 signaling. Int J Clin Exp Med ,8: 21839-21848.

[200] Zhang PP, Meng ZT, Wang LC, Guo LM, Li K (2015). Astragalus polysaccharide promotes the release of mature granulocytes through the L-selectin signaling pathway. Chin Med, 10: 17.

[201] Wang N, Zhang D, Mao X, Zou F, Jin H, Ouyang J (2009). Astragalus polysaccharides decreased the expression of PTP1B through relieving ER stress induced activation of ATF6 in a rat model of type 2 diabetes. Mol Cell Endocrinol, 307: 89-98.

[202] Mao XQ, Yu F, Wang N, Wu Y, Zou F, Wu K, et al. (2009). Hypoglycemic effect of polysaccharide enriched extract of Astragalus membranaceus in diet induced insulin resistant $\mathrm{C} 57 \mathrm{BL} / 6 \mathrm{~J}$ mice and its potential mechanism. Phytomedicine, 16: 416-425.

[203] Hsu AL, Murphy CT, Kenyon C (2003). Regulation of aging and age-related disease by DAF-16 and heatshock factor. Science, 300: 1142-1145.

[204] Zhang H, Pan N, Xiong S, Zou S, Li H, Xiao L, et al. (2012). Inhibition of polyglutamine-mediated proteotoxicity by Astragalus membranaceus polysaccharide through the DAF-16/FOXO transcription factor in Caenorhabditis elegans. Biochem J, 441: 417-424.

[205] Li H, Shi R, Ding F, Wang H, Han W, Ma F, et al. (2016). Astragalus polysaccharide suppresses 6hydroxydopamine-induced neurotoxicity in caenorhabditis elegans. Oxid Med Cell Longev ,2016: 4856761.

[206] Bernardes DJB, Schneeberger K, Vera E, Tejera A, Harley CB, Blasco MA (2011). The telomerase activator TA-65 elongates short telomeres and increases health span of adult/old mice without increasing cancer incidence. Aging Cell, 10:604-621. Vaziri H, Schachter F, Uchida I, Wei L, Zhu X, Effros $\mathrm{R}$, et al. (1993). Loss of telomeric DNA during aging of normal and trisomy 21 human lymphocytes. Am J Hum Genet, 52: 661-667.

[208] Counter CM, Hirte HW, Bacchetti S, Harley CB (1994). Telomerase activity in human ovarian carcinoma. Proc Natl Acad Sci U S A, 91: 2900-2904.

[209] Harley CB, Futcher AB, Greider CW (1990). Telomeres shorten during ageing of human fibroblasts. Nature, 345: 458-460.

[210] Bodnar AG, Ouellette M, Frolkis M, Holt SE, Chiu CP, Morin GB, et al. (1998). Extension of life-span by introduction of telomerase into normal human cells. Science, 279: 349-352.

[211] Jaskelioff M, Muller FL, Paik JH, Thomas E, Jiang S, Adams AC, et al. (2011). Telomerase reactivation reverses tissue degeneration in aged telomerasedeficient mice. Nature, 469: 102-106.

[212] Ait-Ghezala G, Hassan S, Tweed M, Paris D, Crynen G, Zakirova Z, et al. (2016). Identification of telomerase-activating blends from naturally occurring compounds. Altern Ther Health Med, 22 Suppl 2: 614.

[213] Reichert S, Bize P, Arrive M, Zahn S, Massemin S, Criscuolo F (2014). Experimental increase in telomere length leads to faster feather regeneration. Exp Gerontol, 52: 36-38.

[214] Salvador L, Singaravelu G, Harley CB, Flom P, Suram A, Raffaele JM (2016). A natural product telomerase activator lengthens telomeres in humans: a randomized, double blind, and placebo controlled study. Rejuvenation Res, 19: 478-484.

[215] Harley CB, Liu W, Flom PL, Raffaele JM (2013). A natural product telomerase activator as part of a health maintenance program: metabolic and cardiovascular response. Rejuvenation Res, 16: 386-395.

[216] Harley CB, Liu W, Blasco M, Vera E, Andrews WH, Briggs LA, et al. (2011). A natural product telomerase activator as part of a health maintenance program. Rejuvenation Res, 14: 45-56.

[217] Molgora B, Bateman R, Sweeney G, Finger D, Dimler T, Effros RB, et al. (2013). Functional assessment of pharmacological telomerase activators in human $\mathrm{T}$ cells. Cells, 2: 57-66. 